\title{
Huperzine A lowers intraocular pressure via the M3 MAChR and provides retinal neuroprotection via the M1 mAChR: a promising agent for the treatment of glaucoma
}

\author{
Ping Yu ${ }^{1,2 \#} \wedge$, Wen-Pei Dong ${ }^{2,3 \#}$, Ya-Bin Tang ${ }^{1}$, Hong-Zhuan Chen ${ }^{2}$, Yong-Yao Cui ${ }^{2}$, Xiao-Lan Bian ${ }^{1}$ \\ ${ }^{1}$ Department of Pharmacy, Ruijin Hospital, Shanghai Jiao Tong University School of Medicine, Shanghai, China; ${ }^{2}$ Department of Pharmacology, \\ Shanghai Jiao Tong University School of Medicine, Shanghai, China; ${ }^{3}$ Department of General Surgery, Hernia and Abdominal Wall Surgery Center \\ of Shanghai Jiao Tong University, Shanghai Ninth People's Hospital, Shanghai Jiao Tong University School of Medicine, Shanghai, China \\ Contributions: (I) Conception and design: HZ Chen, YY Cui; (II) Administrative support: HZ Chen, YY Cui; (III) Provision of study materials or \\ patients: XL Bian; (IV) Collection and assembly of data: P Yu, YB Tang; (V) Data analysis and interpretation: P Yu, WP Dong; (VI) Manuscript \\ writing: All authors; (VII) Final approval of manuscript: All authors. \\ "These authors contributed equally to this work. \\ Correspondence to: Hong-Zhuan Chen. Department of Pharmacology, Shanghai Jiao Tong University School of Medicine, Shanghai, China. \\ Email: yaoli@shsmu.edu.cn; Yong-Yao Cui. Department of Pharmacology, Shanghai Jiao Tong University School of Medicine, Shanghai, China. \\ Email: yongyaocui@hotmail.com; Xiao-Lan Bian. Department of Pharmacy, Ruijin Hospital, Shanghai Jiao Tong University School of Medicine, \\ Shanghai, China. Email: bxl70029@163.com.
}

Background: Glaucoma is a neurodegenerative disease that shares similar pathological mechanisms with Alzheimer's disease (AD). Drug treatments for glaucoma increasingly rely upon both lowering of intraocular pressure (IOP) and optic nerve protection, as lowering of IOP alone has been unsatisfactory. Huperzine A (HupA) is an acetylcholinesterase inhibitor (AChEI) used for AD. This study investigated the potential of HupA as a treatment for glaucoma.

Methods: The ability of HupA to lower IOP via causing pupil constriction was assessed using New Zealand rabbits. The retinal neuroprotective effects of HupA were assessed in vivo using rat retinas subjected to ischemia-reperfusion (I/R) and in vitro using primary retinal neurons (PRNs) suffering from oxygen-glucose deprivation (OGD).

Results: HupA caused pupil constriction in a dose-time dependent manner which was reversed by the nonselective muscarinic acetylcholine receptor ( $\mathrm{mAChR}$ ) antagonist atropine and the selective $\mathrm{M} 3 \mathrm{mAChR}$ antagonist 4-DAMP. However, HupA had no effect on isolated iris muscle tension and calcium flow indicating an indirect $\mathrm{M} 3 \mathrm{mAChR}$ mediated effect. HupA exerted a neuroprotective effect against I/R and OGD to attenuate the retinal pathological lesion, improve retinal neuronal cell viability, reverse oxidative stress injury by increasing GSH levels and SOD activity, and decreasing MDA content and reduce the retinal neuronal apoptosis by decreasing Bax/Bcl-2 ratio and caspase-3 expression with no effect on the calcium flow tests. The effects were abolished by atropine and the selective M1 mAChR antagonist pirenzepine in OGDinduced PRNs suggesting an indirect M1 mAChR-mediated effect via inhibiting AChE activity to increase endogenous ACh level. Furthermore, HupA increased phosphorylated AKT level and decreased the levels of phosphorylated JNK, P38 MAPK and ERK via M1 mAChR antagonists indicating an involvement of activating the M1 mAChR and the downstream AKT/MAPK signaling pathway in the protective effects of HupA.

Conclusions: HupA could significantly decrease IOP via activating M3 mAChR indirectly and produce retinal neuroprotective effect through M1 mAChR/AKT/MAPK by increasing endogenous ACh level. These investigations demonstrated that HupA was an effective drug in glaucoma treatment and the clinical

$\wedge$ ORCID: 0000-0002-1122-8700. 
application of HupA and other AChEIs for glaucoma patients should be further investigated.

Keywords: Glaucoma; Alzheimer's disease; Huperzine A (HupA); intraocular pressure (IOP); retinal neuroprotection

Submitted Nov 06, 2020. Accepted for publication Jan 29, 2021.

doi: 10.21037/atm-20-8093

View this article at: http://dx.doi.org/10.21037/atm-20-8093

\section{Introduction}

Glaucoma is a chronic progressive optic neuropathy characterized by ongoing damage to the retinal ganglion cells (RGCs) and irreparable vision loss. It is the leading cause of irreversible blindness. By 2040, it is estimated that the global number of glaucoma patients will reach 111.8 million (1). Elevated intraocular pressure (IOP) is believed to be the most important risk factor affecting the occurrence and development of glaucoma (2). Increased IOP can cause oxidative stress, as well as direct damage to the optic nerve resulting in the loss of RGCs and their axons. Retinal blood supply disorders, reperfusion injury, and nutritional deficiencies induced by elevated IOP may also contribute to optic nerve injury in glaucoma patients $(3,4)$. The firstline treatment in the long-term management of glaucoma patients is to decrease the IOP via using clinical medication, laser treatment, or surgery. However, many clinical reports have shown that a proportion of patients still suffered from progressive optic nerve damage despite IOP within or below the normal physiological range. This indicated the involvement of other IOP-independent factors in the progressive damage of RGCs in glaucoma patients (5).

Nowadays, glaucoma is considered to be a multifactorial disease, with the death of RGCs related to many different pathological factors. Studies have suggested that since glaucoma is a chronic and progressive neurodegenerative disease dominated by the loss of neuronal cells in specific areas, it may share a similar pathological process with Alzheimer's disease (AD) (6). Multiple biomarkers of $\mathrm{AD}$ are significantly increased in the aqueous humor of glaucoma patients, and this could eventually lead to RGC death and damage to the optic nerve (7). Patients with neurodegenerative diseases have higher incidences of glaucoma than that of healthy people (8). In AD patients, similar pathological characteristics of glaucoma, including reduced thickness of the RGC layer, enlarged optic nerve disc, and progressive RGC death, were observed $(9,10)$. Studies have reported that various neurodegenerative diseases share a common end-stage pathological process that ultimately results in apoptosis of nerve cells induced by oxidative stress. Therefore, it is believed that drugs effective in the treatment of $\mathrm{AD}$ may also be used to treat glaucoma, and similarly, therapeutic options for glaucoma may be used to treat other neurodegenerative diseases (11). So far, the therapeutic treatments for glaucoma have not been ideal because of the complex etiology of glaucoma and the imprecise pathogenesis of optic nerve damage. One effective drug treatment strategy may be to simultaneously reduce IOP and control the development of glaucomatous optic neuropathy. Indeed, current international efforts have focused on developing new drugs that can not only target ocular hypertension but also glaucomatous optic neuropathy.

Huperzine A (HupA) is a highly active alkaloid extracted and isolated from the Huperzia serrata plant in China. It is a reversible, highly effective and specific acetylcholinesterase inhibitor (AChEI) that increases acetylcholine (ACh) levels. HupA has been used therapeutically to restore and enhance memory function in $\mathrm{AD}$ patients with remarkable success and is widely used in China (12). Studies have demonstrated that HupA decreased amyloid beta peptide $(\mathrm{A} \beta)$ production in the brain via activating the M1 muscarinic acetylcholine receptors/protein kinase $\mathrm{C}$ (M1 mAChR/PKC) cascade pathway to regulate $\alpha$ - and $\beta$-secretase activity (13). HupA has also been shown to improve cognitive impairment induced by chronic cerebral ischemia via activating the nicotinic acetylcholine receptors (nAChR) (14). In addition, bis(12)-hupyridone, a derivative of HupA, showed a substantial protective effect on glutamate-induced neuronal excitotoxicity, by promoting dendritization and differentiation of hippocampal neurons in adult mice through activating the $\alpha-7 \mathrm{nAChRs}$ and the downstream phosphoinositide-3-kinase-protein kinase B/AKT (PI3K/ AKT) signaling cascade $(15,16)$.

However, there has been little research into the application of HupA in glaucoma patients. As an AChEI, 
whether HupA can reduce IOP and also exhibit retinal neuroprotective effects in glaucoma patients is still unknown. Therefore, exploring the effects of HupA on glaucoma and its regulatory mechanisms is conducive to expanding its application and development in the clinical treatment of glaucoma. In this study, we evaluated the roles and mechanisms of HupA in lowering IOP and retinal neuroprotection. These results will provide a theoretical basis for the application of HupA in glaucoma treatment and may also lead to the identification of novel therapeutic targets.

We present the following article in accordance with the ARRIVE reporting checklist (available at http://dx.doi. org/10.21037/atm-20-8093).

\section{Methods}

\section{Measurement of pupil diameter in New Zealand rabbits}

To observe the effects of HupA on pupil size, male New Zealand white rabbits were randomly divided into six groups. HupA eye drops were administered at concentrations of $0.001 \%, 0.01 \%$, or $0.1 \%$. Two treatment groups were administered $2 \%$ pilocarpine and $0.25 \%$ physostigmine as positive drug controls. Normal saline eye drops were given to the blank control group. Each group consisted of more than 5 rabbits. The pupil diameter was measured at $15,30,60,90,120,150,180,210$, and 240 minutes after the administration of the eye drops. To determine which $\mathrm{mAChR}$ was involved, animals were treated with the nonselective $\mathrm{mAChR}$ antagonist atropine, the M1 mAChR antagonist pirenzepine, the M2 mAChR antagonist gallamine, or the $\mathrm{M} 3 \mathrm{mAChR}$ antagonist 4-DAMP 30 minutes prior to the administration of $0.01 \%$ HupA. This study was approved by the Shanghai Jiao Tong University School of Medicine Institutional Animal Care \& Use Committee (No. A-2015-044). Experiments were performed in compliance with the principles and guidelines of the National Institutes of Health Guide for the Care and Use of Laboratory Animals.

\section{In vitro culture of primary retinal neurons (PRNs)}

PRNs were harvested from neonatal Sprague-Dawley (SD) rats in $24 \mathrm{~h}$ was previously described (17). Briefly, the retinal neurons were harvested from the scleral tissue and the pigmented epithelium by digestion in an enzyme mixture consisting of $0.125 \%$ trypsin, $32 \mathrm{U}$ per $\mathrm{mL}$ papain, $0.01 \%$
L-cysteine, and $0.02 \%$ EDTA. A monoplast suspension was prepared and inactivated by Dulbecco's Modified Eagle Medium (DMEM; Gibco, USA) with 10\% fetal bovine serum (FBS; Sigma, USA) after being triturated thoroughly. PRNs were seeded onto poly-L-lysine-coated plates (Sigma, USA) and incubated with DMEM containing 10\% FBS overnight. The cells were then cultured in neurobasal medium containing 2\% B27, $2 \mathrm{mM} \mathrm{L}$-glutamine, $100 \mathrm{U} / \mathrm{mL}$ penicillin and $100 \mu \mathrm{g} / \mathrm{mL}$ streptomycin (Gibco, USA) at $37^{\circ} \mathrm{C}$ in a humidified $5 \% \mathrm{CO}_{2}$ incubator. Cells were used for experiments at day 7 .

\section{Oxygen-glucose deprivation (OGD) model}

The neurobasal media for the PRNs was replaced with OGD media (1.8 $\mathrm{mM} \mathrm{CaCl}_{2}, 0.814 \mathrm{mM} \mathrm{MgCl}, 5.33 \mathrm{mM}$ $\mathrm{KCl}, 26.19 \mathrm{mM} \mathrm{NaHCO}, 68.97 \mathrm{mM} \mathrm{NaCl}, 0.906 \mathrm{mM}$ $\mathrm{NaH}_{2} \mathrm{PO} 4$, and $10 \mathrm{mM}$ sucrose, $\mathrm{PH}$ 7.4; Sigma, USA) which was deoxygenate with $95 \% \mathrm{~N}_{2}$ and $5 \% \mathrm{CO}_{2}$ by bubbling for 1 hour. The OGD injury to the PRNs was induced in an anaerobic chamber with $95 \% \mathrm{~N}_{2}, 5 \% \mathrm{CO}_{2}$ and $0.02-0.1 \%$ $\mathrm{O}_{2}$ at $37^{\circ} \mathrm{C}$ for 4 hours followed by incubation with normal media (which contained the same composition as the OGD media except that the sucrose was replaced by D-Glucose) under normoxic atmosphere. The control group was cultured in normal media for the parallel amount of time. HupA (WuXi AppTec, China), pilocarpine, physostigmine, atropine, and pirenzepine were added to the cells 30 minutes prior to OGD treatment. Cell viability was assessed using the Cell Counting Kit-8 (CCK-8, Dojindo, Japan).

\section{Retinal ischemia reperfusion (I/R) injury in animals}

Male SD rats (weighting 200-250 g each) were housed in a standard room with humidity ranging from 30 $55 \%$ and temperature of $22-25^{\circ} \mathrm{C}$ under a 12 -hour day-night rhythm and fed ad libitum food and water according to the Association for Research in Vision and Ophthalmology statement. Rats were subjected to I/R injury as previously reported (18). In detail, anesthesia was achieved via intraperitoneal injection of pentobarbital sodium $(30 \mathrm{mg} / \mathrm{kg})$. After full dilation, the anterior chamber of the left eye was cannulated with a 27 -gauge needle connected to a bottle of saline. The IOP of $110 \mathrm{mmHg}$ was maintained for 50 minutes before withdrawing the needle. SD rats were then randomly separated into ten groups (with 5 or more rats per group). In the HupA-treated rats, $0.01 \%$ HupA was dropped 
into the left eye four times per day for 3 days before and after the I/R operation and no operation was conducted in the right eye. The following three drugs were used as positive controls: $2 \%$ pilocarpine and $0.25 \%$ physostigmine administered as for HupA, and $0.005 \%$ latanoprost prostaglandin administered once daily. The control group had no treatment and no operation.

\section{Histopathological study using hematoxylin and eosin staining}

Three days after the I/R operation, rats were anesthetized with pentobarbital sodium $(30 \mathrm{mg} / \mathrm{kg}$ ) by intraperitoneal injection. The eyes were processed and fixed in $4 \%$ paraformaldehyde in phosphate buffered saline (PBS). After removing the anterior segment and lenses, the eyecups were dehydrated in alcohol and embedded in paraffin. Retinal cross-sections were prepared and stained with hematoxylin and eosin $(\mathrm{H} \& \mathrm{E})$. Images of the slices were analyzed at about 2-3 disc diameter from the optic nerve with an image analysis system.

\section{Immunofluorescence staining}

Paraffin sections were baked in an oven at $60^{\circ} \mathrm{C}$ for $2-3$ hour followed by incubated in antigen repair solution at $100{ }^{\circ} \mathrm{C}$ for 30 minutes, then cooled to room temperature. Samples were then completely immersed in a xylene and alcohol gradient. Following this, the slices were dried and sealed at room temperature for 1 hour with sealing solution $(10 \%$ normal goat serum plus $0.3 \%$ Triton X100 dissolved in PBS). After washing off the blocking liquid, sections were incubated with caspase-3 (1:100; Cell Signaling Technology, USA) overnight at $4{ }^{\circ} \mathrm{C}$ in a wet box followed by incubation with a secondary antibody (1:5,000; Cell Signaling Technology, USA) at room temperature for 2 hours. After washing, samples were dyed with 4',6-diamidino2-phenylindole (DAPI) for 5 minutes. Photographs were taken under confocal microscopy and analyzed.

\section{Western blot analysis}

Total protein was prepared from the retinal neurons and tissues of different experimental groups using lysis buffer. Samples were centrifuged and the resultant protein samples were loaded onto $10 \%$ sodium dodecyl sulphatepolyacrylamide gel electrophoresis (SDS-PAGE) gels and transferred to polyvinylidene difluoride (PVDF) membranes. The membranes were incubated with the following primary antibodies $(1: 1,000)$ overnight at $4{ }^{\circ} \mathrm{C}$ : Bax, Bcl-2, total caspase-3, P-AKT, AKT, P-P38 MAPK, P38 MAPK, P-ERK, ERK, P-JNK, JNK, and glyceraldehyde 3-phosphate dehydrogenase (GAPDH) (Cell Signaling Technology, USA). Following thorough washing, the membranes were incubation with a horseradish peroxidase (HRP) conjugated secondary antibody (1:5,000; Zhongshan Biotechnology Co., China) for 1 hour. Protein bands were visualized using an enhanced chemiluminescence (ECL) kit (Pierce Chemical, USA). The relative intensities of the proteins were analyzed using Image J software.

\section{Polymerase chain reaction (PCR) analysis}

Reverse transcription polymerase chain reaction (RT-PCR) was used to examine the messenger RNA (mRNA) levels of RGCs-selected markers including Nfl, Nrn1, Sncg, Thy1 and Fem1c (the primer sequences showed in Table 1) in the experimental retinal tissue and the PRNs. Briefly, the total RNA was incubated with QuantiTect Reverse Trancriptase (Takara, Dalian, China) at $37^{\circ} \mathrm{C}$ for 15 minutes and at $80{ }^{\circ} \mathrm{C}$ for 5 seconds. A final $20 \mu \mathrm{L}$ mixture consisted of $2 \mu \mathrm{L}$ reversetranscriptase (RT) mixture, $7.2 \mu \mathrm{L}$ SYBR green PCR reagent (Takara, Dalian, China), $0.4 \mu \mathrm{L}$ forward primers and $0.4 \mu \mathrm{L}$ reverse primers, and $10 \mu \mathrm{L}$ diethylpyrocarbonate (DEPC) $\mathrm{H}_{2} \mathrm{O}$. Gene expression levels were normalized with GAPDH. The results were analyzed using the $2^{-\Delta \Delta C T}$ method.

\section{Analysis of acetylcholinesterase (ACbE) activity}

The cholinesterase activity was assayed with a commercial kit (Acetylcholinesterase Activity Assay Kit, Sigma, USA) according to the manufacturer's instruction.

\section{Detection of ACb using liquid chromatography with tandem mass spectrometry (LC-MS/MS)}

After OGD treatment, the supernatants of the PRNs in each experimental group were collected for ACh detection. Retinal tissue from the different groups were firstly homogenized using normal saline (1:9). Following this, $100 \mu \mathrm{L}$ of the samples was precipitated with $300 \mu \mathrm{L}$ cold acetonitrile and centrifuged at $13,000 \mathrm{~g}$ at $4{ }^{\circ} \mathrm{C}$ for 10 minutes. ACh levels were determined by LC-MS/MS as previously reported (19).

\section{Detection of iris muscle tension in vitro}

New Zealand white rabbits were anesthetized with 
Table 1 RGC gene-specific primers sequence

\begin{tabular}{lll}
\hline Primer & Forward $\left(5^{\prime}\right.$ to $\left.3^{\prime}\right)$ & Reverse $\left(5^{\prime}\right.$ to $\left.3^{\prime}\right)$ \\
\hline Rat-Nfl & TGAGCCAGGTAGCCGCCATC & CTCAGCACCTCCTCCTCGTAGC \\
Rat-Nrn1 & TACCTGGTGCAGGCCGTGAG & CCTTCCTGGCAATCCGTAAGAGC \\
Rat-Sncg & CAAGTGTAACCTCGGTGGCTGAG & TCACCTCCACTCTTGGCCTCTTC \\
Rat-Thy1 & CTGACAGCCTGCCTGGTGAAC & CCTCATCCTTGGTGGTGAAGTTGG \\
Rat-Fem1c & CTCTGCATCTGGCTGTGGACAAG & ACGATGACACGAGCAGCAAGAC \\
Rat-GAPDH & GACAACTTTGGCATCGTGGA & ATGCAGGGATGATGTTCTGG \\
\hline
\end{tabular}

pentobarbital sodium $(30 \mathrm{mg} / \mathrm{kg})$ by intraperitoneal injection. Eyeballs were quickly removed and immediately placed in Krebs solution containing 95\% $\mathrm{O}_{2}$ and $5 \% \mathrm{CO}_{2}$. The eyeball was incised along the corneal scleral margin and the iris was completely separated from cornea, lens, and other tissues with a blunt stripper. After washing twice, the prepared iris was pulled through two hooks separately. All effort was made to avoid dragging the iris. This was then placed into a circulating water bath filled with $10 \mathrm{~mL}$ Krebs liquid at $37{ }^{\circ} \mathrm{C}$ and continuously administered with a mixture of $5 \% \mathrm{CO}_{2}$ and $95 \% \mathrm{O}_{2}$. The Krebs solution was changed once every 10 minutes and balanced for at least 45 minutes. One end of the iris was connected to the hook and fixed. The other end was connected to the tension transducer using sutures. After the iris was hung, the resting tension was adjusted with a force of about $0.5 \mathrm{~g}$. The changes in iris muscle tension were recorded. The final concentrations of carbachol, pilocarpine (Pilo), physostigmine (Phy), and HupA in the water bath circulation tank were $10^{-7}$, $3 \times 10^{-7}, 10^{-6}, 3 \times 10^{-6}, 10^{-5}, 3 \times 10^{-5}, 10^{-4}$, and $3 \times 10^{-4} \mathrm{M}$. The dose-effect curve of the iris muscle tension was linearized according to double-reciprocal transformation (modified Lineweaver-Burk) to obtain the Emax (maximum effect of drug action). Emax of carbachol was used as a control in this experiment.

\section{Calcium flow test}

Chinese hamster ovary cells $(\mathrm{CHO})$ transfected with the human M1 and M3 mAChRs (CHO-M1, CHO-M3) were cultured with Ham's F12 medium with $10 \%$ FBS and $200 \mu \mathrm{g} / \mathrm{mL}$ zeocin or $400 \mu \mathrm{g} / \mathrm{mL}$ geneticin. When the cells had converged to about $80-90 \%$, they were transferred to 96-well plates. The FLIPR Calcium 4 dye (Molecular Devices, USA) was completely dissolved in Hank's Balanced Salt Solution (HBSS) and probenecid was added. The prepared calcium ion dyes were added to the 96-well plates $(50 \mu \mathrm{L} /$ well $)$ with an equal volume of cell culture medium. The plates were incubated at $37^{\circ} \mathrm{C}$ for 30 minutes followed by incubation at room temperature for 15 minutes. Different drug solutions (Pilo, Phy, and HupA at $10 \mu \mathrm{M}$ ) were added to the cells and intracellular calcium levels were assessed. The continuous determination time was $2-3$ minutes. A group of data could be obtained every 1.52 seconds.

\section{Detection of cytotoxicity (LDH)}

Lactate dehydrogenase kit (LDH, Dojindo, Japan) was operated as the manufacturer's instruction. Briefly, primary retinal neuronal cells were seeded in 96-well plate with drug treatment and cultured for the required time. $10 \mu \mathrm{L}$ lysate was added to the high control well sample, and incubated at $37^{\circ} \mathrm{C}$ for $30 \mathrm{~min}$ and $100 \mu \mathrm{L}$ working solution was added to each well and incubated at room temperature in the dark. After adding $50 \mu \mathrm{L}$ stop solution, absorbance of the sample was detected with a multifunctional microplate reader at $490 \mathrm{~nm}$ wavelength. Cell damage rate $=($ sample well-blank control well)/(high control well-blank control well) $\times 100 \%$.

\section{Detection of oxidative stress injury indicators (MDA, $S O D, G S H)$}

The cells were inoculated according to the experimental requirements. After dropping supernatant, lysis solution was added and incubated for 30 minutes. Samples were collected and centrifuged as required. The rat retina was mixed with normal saline at a ratio of 1:9. The tissue was completely broken by shaking and grinding with a homogenizer, and the supernatant was centrifuged as required to be measured. The detection of each index (MDA, SOD, GSH, Nanjing Jiancheng Bioengineering Institute, China) was carried out according to the manufacturer's instructions. 

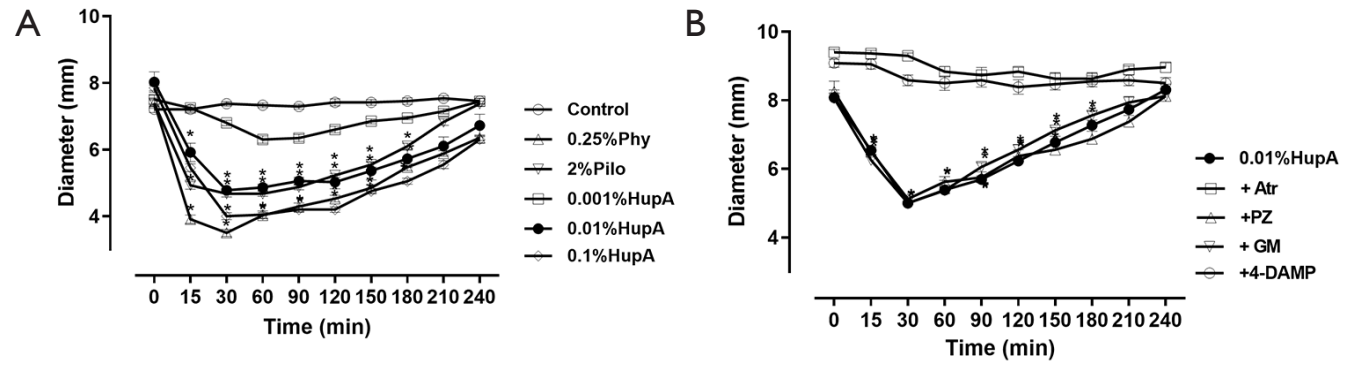

Figure 1 The effects of huperzine A (HupA) on the rabbit pupil diameter. After treatment with different concentrations of HupA, the diameter of the rabbit pupil was significantly contracted over time in a dose-dependent manner which was reversed by the M3 mAChR antagonist atropine (Atr) and 4-DAMP. The positive drug control groups were $2 \%$ pilocarpine (Pilo) and 0.25\% physostigmine (Phy). (A) The effects of HupA on the rabbit pupil diameter; (B) the effects of the nonselective mAChR antagonist atropine (Atr), the selective M1 mAChR antagonist pirenzepine (PZ), the M2 mAChR antagonist gallamine (GM), and the M3 mAChR antagonist 4-DAMP on pupil diameter after HupA treatment. Data are expressed as mean \pm SEM, $\mathrm{n} \geq 5$. ${ }^{*} \mathrm{P}<0.05$, compared with the corresponding control group. SEM, standard error of the mean.

\section{Statistical analysis}

All data were statistically analyzed using ANOVA in Prism 8.0 (Graphpad software, USA) and the data were expressed as the mean \pm SEM. The differences were performed followed by Tukey's multiple comparisons test for selected pairs if appropriate. Differences between means were considered to be statistically significant if $\mathrm{P}<0.05$.

\section{Results}

\section{The effects of HupA on pupil diameter in rabbits}

The dose-effect/time-effect curve showed that different concentrations of HupA $(0.001 \%, 0.01 \%$, and $0.1 \%)$ induced pupil contraction in a dose-dependent manner compared with the control group (saline treatment). Compared with $2 \%$ pilocarpine and $0.25 \%$ physostigmine, $0.01 \%$ HupA eye drops had a similar dose-effect/time-effect curve. All three drugs caused pupil contraction immediately after administration of the eye drops, and reached the maximum pupil constriction by 30 minutes, and this gradually weakened after 60 minutes. The effects on pupil contraction could be maintained for more than 3 hours. In addition, the effect of $0.01 \%$ HupA was similar to that of $2 \%$ pilocarpine (Figure 1A). To determine the mAChR subtype mediating the HupA effects, different pharmacological antagonists were administered 30 minutes prior to $0.01 \%$ HupA treatment (Figure 1B). The results demonstrated that the nonselective $\mathrm{mAChR}$ antagonist atropine, and the selective M3 mAChR antagonist 4-DAMP could reverse the effects of $0.01 \%$ HupA on pupil contraction, while the selective $\mathrm{M} 1 \mathrm{mAChR}$ antagonist pirenzepine, and the selective M2 mAChR antagonist gallamine had little effect on pupil contraction in HupA-treated animals (Figure 1B). These results suggested that the $\mathrm{M} 3 \mathrm{mAChR}$ mediated the effect of HupA on constriction to lower IOP.

\section{Effects of HupA on isolated iris muscle contraction and intracellular calcium flow}

Further experiments were conducted to verified whether HupA could cause direct excitation of the iris muscles to lower IOP or whether the effect was due an indirect activation of the $\mathrm{mAChR}$ via enhanced production of endogenous ACh. The mAChR agonists carbachol and pilocarpine caused the isolated iris to contract, which had definite pupil contraction effect in vivo, while physostigmine and HupA had no effect on the contraction of the isolated iris (Figure 2A). No significant changes in calcium flow signals were detected in the cytoplasm of CHO-M3 cells stimulated by HupA and physostigmine, while a significant calcium signal was detected in pilocarpine-treated cells (Figure 2B). Therefore, these results confirmed that the ability of HupA to lower IOP via pupil contraction was not mediated by direct stimulation of the choline receptors, but rather through indirect activation of the $\mathrm{M} 3 \mathrm{mAChR}$ via inhibition of AChE activity to increase endogenous ACh level. 

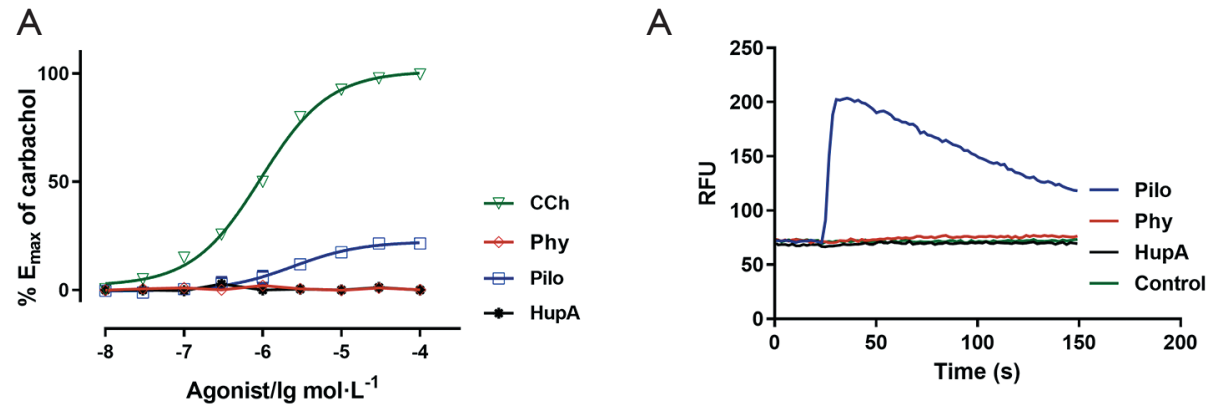

Figure 2 HupA did not cause the isolated iris muscle to contract, nor did it affect intracellular calcium flow. (A) Iris muscle contraction after treatment with HupA, carbachol, Phy, and Pilo; (B) detection of the intracellular calcium flow in CHO-M3 after HupA, Phy, and Pilo treatment. Data are expressed as mean \pm SEM, $\mathrm{n} \geq 5$ rabbits or 3 independent experiments. HupA, huperzine A; CCh, carbachol; Phy, physostigmine; Pilo, pilocarpine; RFU, relative fluorescence units; SEM, standard error of the mean.

The protective effects of HupA on ischemia/reperfusion (I/ $R$ ) and oxygen glucose deprivation (OGD) induced retinal neuronal damage

In this experiment, the pathological damage of $\mathrm{I} / \mathrm{R}$ in rat retinas was assessed. H\&E staining (Figure $3 A$ ) showed that the retinal cells were loosely arranged in each layer. However, the morphology and structure changed significantly in the rats subjected to I/R. The thickness of whole retina, the inner nuclear layer (INL), and the inner platform layer (IPL) of the I/R group were significantly thinner and the number of RGCs in the ganglion cell layer (GCL) was also significantly reduced compared to the normal group $(\mathrm{P}<0.01)$. Compared with the I/R group, $2 \%$ pilocarpine, $0.25 \%$ physostigmine, $0.005 \%$ latanoprost, and $0.01 \%$ HupA significantly improved the pathological damage of the retina by increasing the retinal thickness (Figure $3 B, C, D$ ) and the RGC count (Figure $3 E, \mathrm{P}<0.05$ ). The ganglion cell genes Sncg, Fem1c, Thy1, Nrn1, and Nfl are predominately expressed in surviving RGCs and shut down during the process of retinal neuronal damage (20). In this study, retinal neuronal injury caused by I/R significantly decreased the mRNA levels of Sncg, Fem1c, Thy1, Nrn1, and $\mathrm{Nfl}$ compared with the control group (Figure $3 F$ ). Treatment with HupA, pilocarpine, and physostigmine reversed this, resulting in up-regulated expression, while latanoprost has no significant effect. This suggested that $0.01 \%$ HupA prevented I/R-induced retinal pathological damage and exerted a retinal neuroprotective effect in the in vivo model.

In the in vitro experiments, OGD significantly decreased the viability of the PRNs $(68.6 \% \pm 6.6 \%)$ and increased cytotoxicity $(41.4 \% \pm 5.8 \%)$. Treatment with HupA, pilocarpine, and physostigmine enhanced the survival of the PRNs and relieved the cytotoxicity in a dose-dependent manner (Figure 3G,H). Compared with the OGD group, 1 $\mu \mathrm{M}$ HupA, pilocarpine, and physostigmine increased cell viability to $88.1 \% \pm 9.7 \%, 86.4 \% \pm 10.3 \%$, and $86.8 \% \pm 11.9 \%$, respectively, and reduced cytotoxicity to $32.8 \% \pm 4.7 \%$, $35.7 \% \pm 1.8 \%$, and $32.8 \% \pm 1.5 \%$, respectively. OGD-induced decreased mRNA levels of Sncg, Fem1c, Thy1, Nrn1, and $\mathrm{Nfl}$ in PRNs were also reversed by HupA, pilocarpine and physostigmine (Figure 3I). These results indicated that HupA $(1 \mu M)$ could resist OGD-induced retinal neuronal cell injury and was consistent with the in vivo experiments. Altogether, these results suggested that HupA produced a significant retinal neuronal protective effect against damage induced by I/R and OGD in both the in vivo and in vitro models.

\section{The effects of HupA on retinal neuronal oxidative stress induced by $I / R$ and $O G D$}

Oxidative stress is an important risk factor in the process of optic nerve degeneration (21). Retinal neuronal tissues and cells suffering from I/R and OGD showed obvious abnormal changes in the oxidative stress index. Compared with the control group, glutathione (GSH) content (Figure $4 A, B$ ) and superoxide dismutase (SOD) activity (Figure $4 C, D$ ) were significantly decreased, while malondialdehyde (MDA) levels were significantly increased (Figure $4 E, F$ ) in the I/R and OGD-injured groups. Treatment with HupA, pilocarpine, and physostigmine partially mitigated these I/R and OGD-induced effects. HupA showed a more superior effect than pilocarpine (a mAChR agonist) 


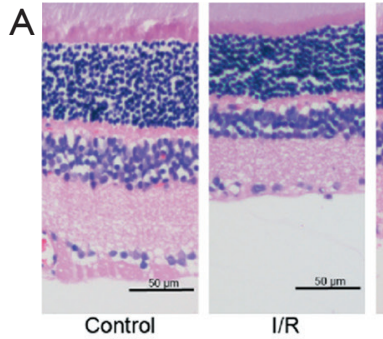

B

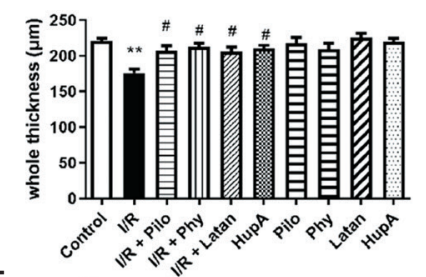

$\mathrm{F}$
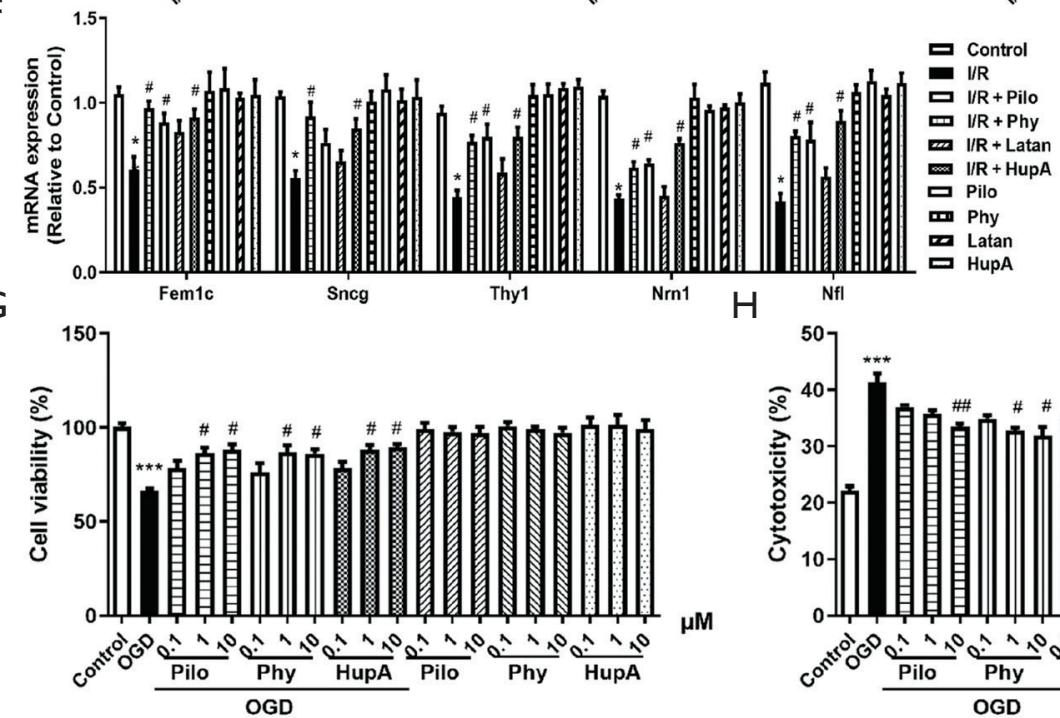

I

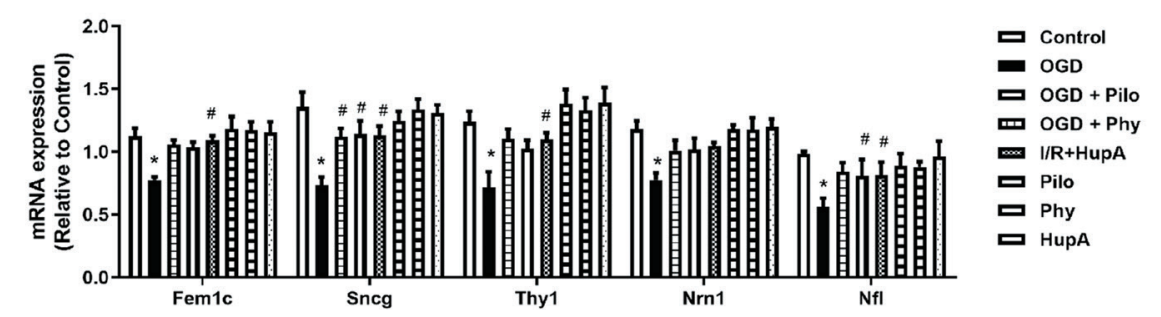

Figure 3 HupA significantly protected the retinal neuronal injury induced by I/R and OGD. (A) H\&E staining of rat retinal slices from the different groups; (B,C,D) thickness of the whole retinas, inner platform layer (IPL) and inner nuclear player (INL) of each different group; (E) cell count of RGCs in the ganglion cell layer (GCL); (F,I) the mRNA expression levels of retinal selected markers including Sncg, Fem1c, Thy1, Nrn1, and Nfl as detected by PCR in I/R-induced retinal tissue or OGD-induced PRNs; (G) cell viability of OGD-induced PRNs detected by CCK-8 kit; (H) cytotoxicity of PRNs induced by OGD detected using the LDH kit. Data are expressed as mean \pm SEM, $\mathrm{n} \geq 5$ rats or 3 independent experiments. ${ }^{*} \mathrm{P}<0.05,{ }^{* *} \mathrm{P}<0.01,{ }^{* * *} \mathrm{P}<0.001$, compared with the control group; ${ }^{\#} \mathrm{P}<0.05,{ }^{\# \#} \mathrm{P}<0.01$, compared with the OGD or I/R group. HupA, huperzine A; I/R, ischemia/reperfusion; OGD, oxygen glucose deprivation; H\&E, hematoxylin and eosin; PRN, primary retinal neuron; CCK-8, cell count kit 8; LDH, lactate dehydrogenase; Pilo, pilocarpine; Phy, physostigmine; Latan, latanoprost; SEM, standard error of the mean. 


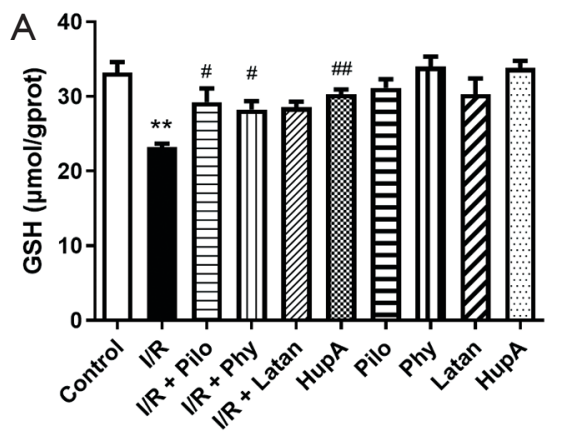

B
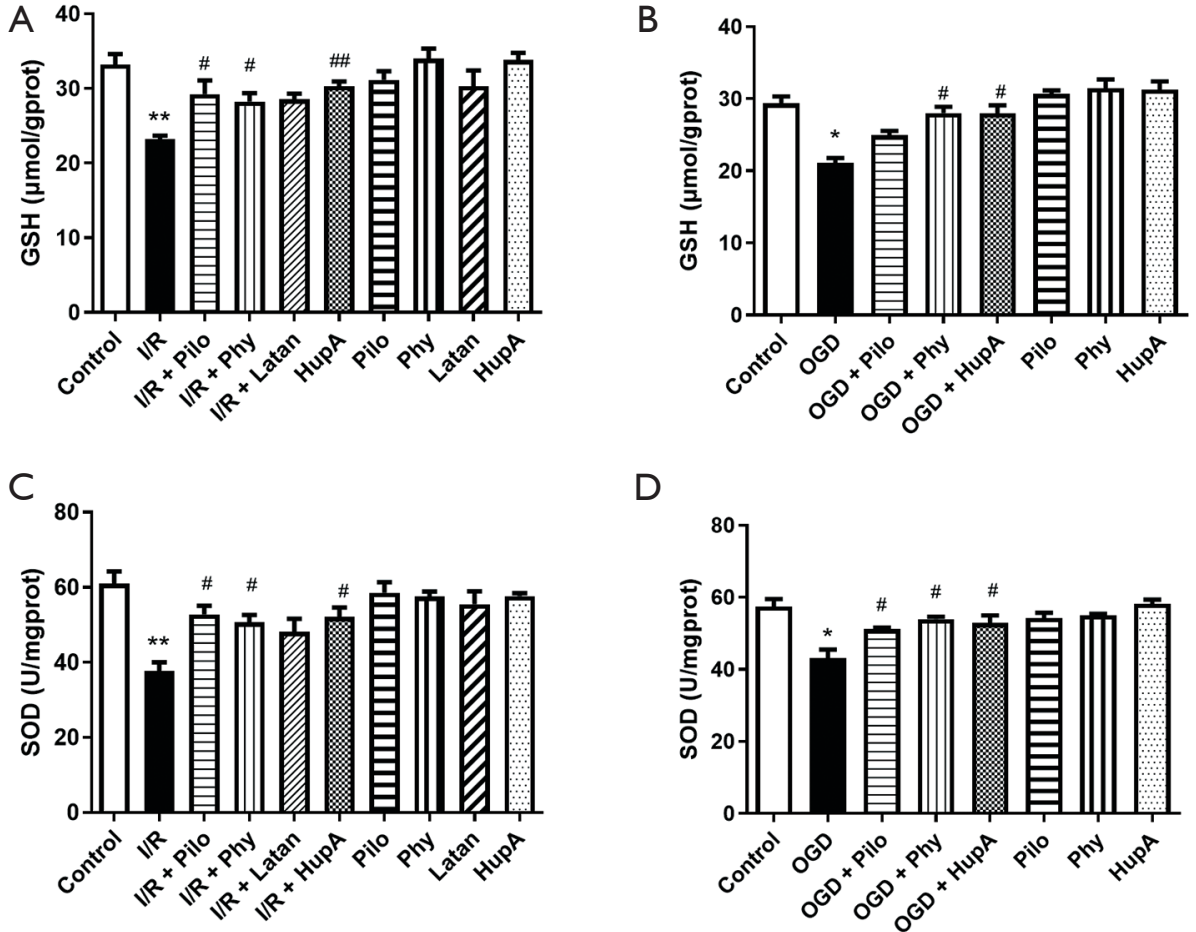

D
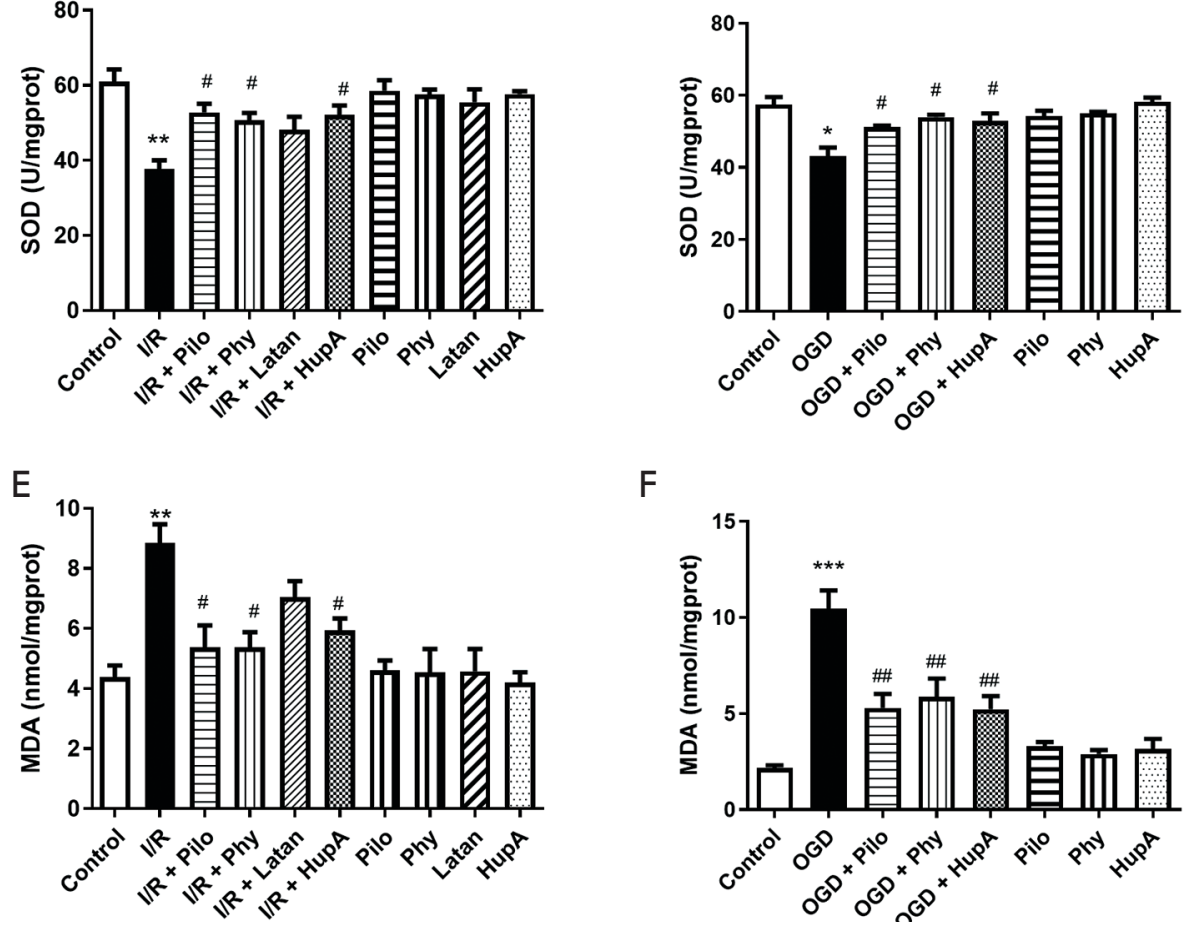

F

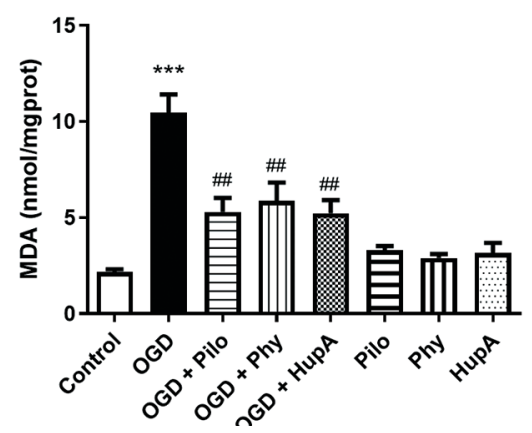

Figure 4 HupA regulated oxidative stress induced by I/R and OGD in retinal neuronal cells. (A,B) GSH levels in retinal tissue subjected to I/R and in PRNs subjected to OGD; (C,D) SOD activity in retinal tissue and neurons; (E,F) MDA level in retinal tissue and neurons. Data are expressed as mean $\pm \mathrm{SEM}, \mathrm{n} \geq 5$ rats or 3 independent experiments. ${ }^{*} \mathrm{P}<0.05,{ }^{* *} \mathrm{P}<0.01$, ${ }^{* * *} \mathrm{P}<0.001$, compared with the control group; ${ }^{\#} \mathrm{P}<0.05,{ }^{~ \#} \mathrm{P}<0.01$, compared with the I/R or OGD group. HupA, huperzine A; I/R, ischemia/reperfusion; OGD, oxygen glucose deprivation; PRN, primary retinal neuron; Pilo, pilocarpine; Phy, physostigmine; Latan, latanoprost; GSH, glutathione; SOD, superoxide dismutase; MDA, malondialdehyde; SEM, standard error of the mean.

and physostigmine (an AChEI). Latanoprost (a selective prostaglandin F2 $\alpha$ receptor agonist) regulated SOD activity, as well as GSH and MDA content to some extent and improved oxidative stress levels in I/R-induced retinal nerve injury, but there was no statistical significance $(\mathrm{P}>0.05)$. The results showed that HupA could alleviate oxidative stress and reduce the damage to the retinal nerve caused by $I / R$ and OGD.
The effects of HupA on apoptosis-related protein expression in retinal tissue and neurons subjected to I/R and OGD

Apoptosis of retinal neurons induced by oxidative stress is involved in the pathological process of glaucoma and has been recognized as the ultimate pathway of optic nerve injury and degeneration (22). In this study, in vivo experiments demonstrated that $\mathrm{I} / \mathrm{R}$ induced retinal neuronal 
A

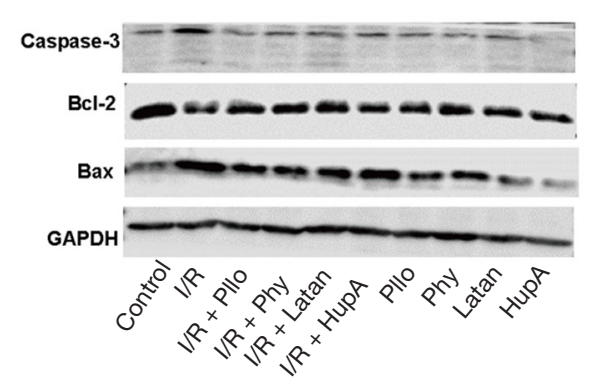

B

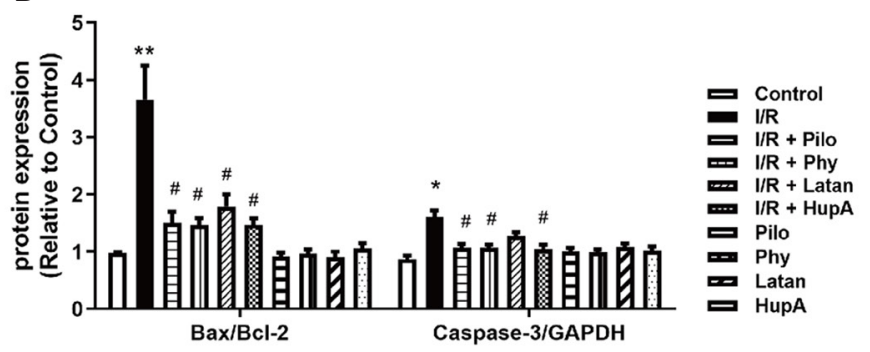

C
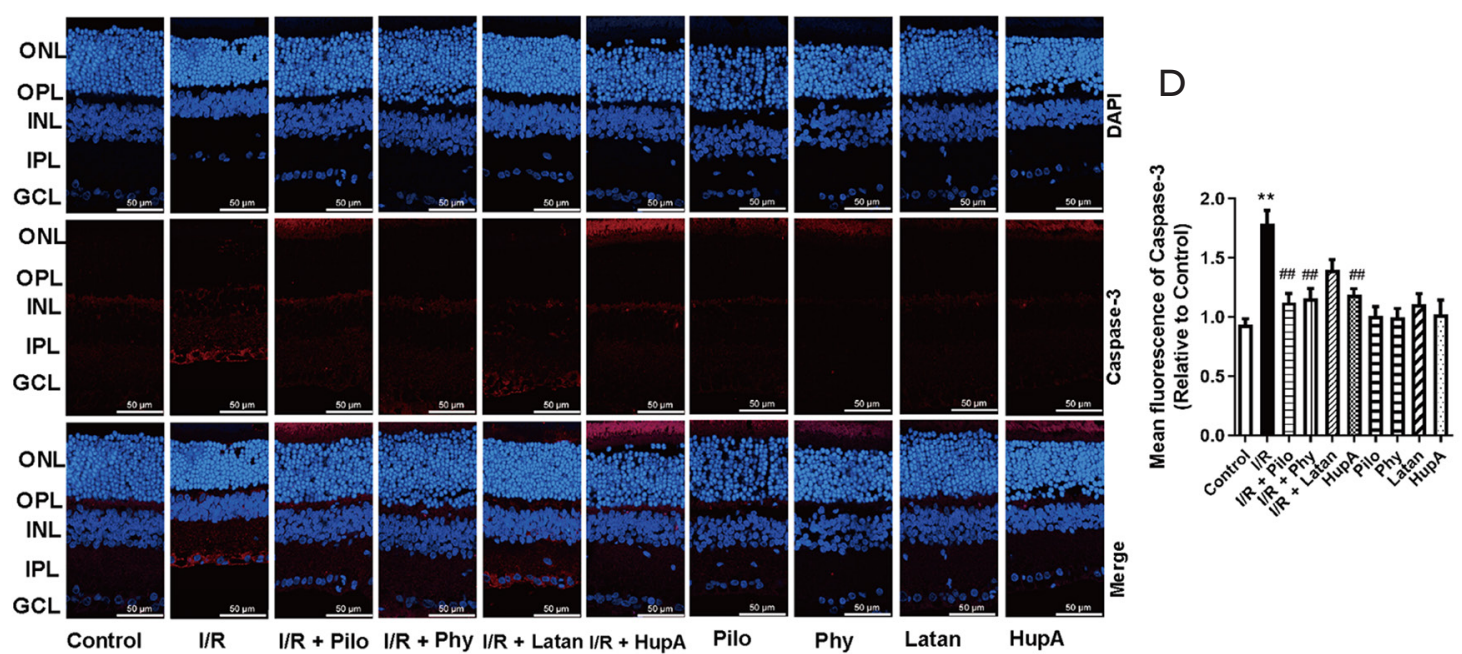

E

$\mathrm{F}$
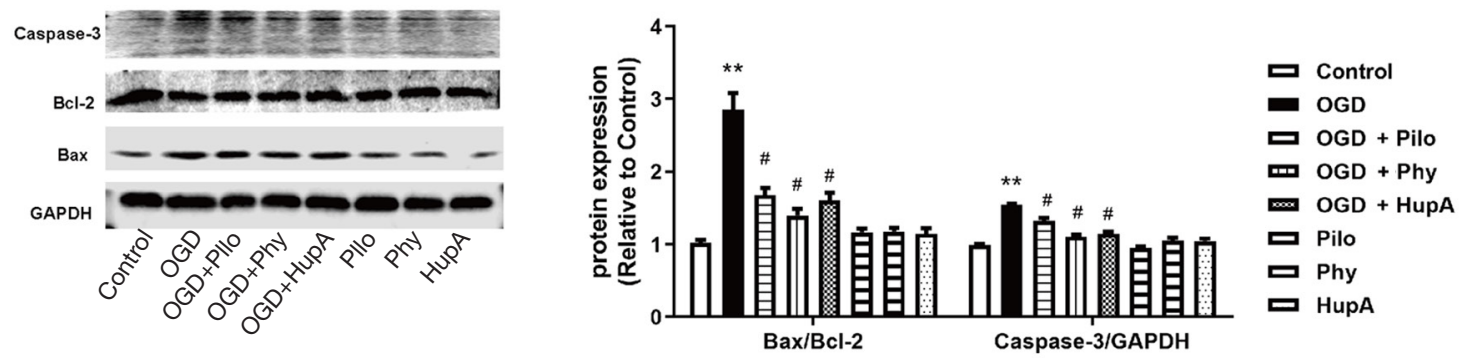

Figure 5 HupA protected against retinal neurons apoptosis induced by I/R and OGD. (A,B) The expression and analysis of apoptosis-related proteins including caspase-3, Bcl-2, and Bax in I/R-induced rat retinal tissue detected by western blot analysis; (C,D) caspase-3 expression and analysis as detected by immunofluorescent staining of rat retinal tissue subjected to I/R treatment; (E,F) the expression and analysis of caspase-3, Bcl-2, and Bax in OGD treated PRNs detected by western blotting. Data are expressed as mean $\pm \mathrm{SEM}, \mathrm{n} \geq 5$ rats or 3 independent experiments. ${ }^{* *} \mathrm{P}<0.01,{ }^{*} \mathrm{P}<0.05$, compared with the control group; ${ }^{\sharp} \mathrm{P}<0.05,{ }^{\# \prime} \mathrm{P}<0.01$ compared with the OGD group. HupA, huperzine A; I/R, ischemia/reperfusion; OGD, oxygen glucose deprivation; PRN, primary retinal neuron; Pilo, pilocarpine; Phy, physostigmine; Latan, latanoprost; GAPDH, glyceraldehyde 3-phosphate dehydrogenase; IHC, immunofluorescence; OPL, outer platform layer; IPL, inner platform layer; ONL, outer nuclear layer; INL, inner nuclear layer; GCL, ganglion cell layer; SEM, standard error of the mean. 
oxidative stress injury and triggered abnormal expressions of apoptosis-related proteins including increased caspase-3 expression and $\mathrm{Bax} / \mathrm{Bcl}-2$ ratio. These effects were reversed by HupA, pilocarpine, and physostigmine but not by latanoprost (Figure $5 A, B$ ). Immunofluorescence staining of retinal tissue sections also showed higher intensity of caspase-3 in the I/R group. Treatment with HupA, pilocarpine or physostigmine decreased the intensity, but there was no significant difference in the latanoprost group compared with the I/R group (Figure 5C,D). Similarly, HupA, pilocarpine, and physostigmine significantly regulated the expression of apoptosis-related proteins in PRNs subjected to OGD and alleviate retinal nerve injury by decreasing caspase- 3 expression and $\mathrm{Bax} / \mathrm{Bcl}-2$ ratio (Figure 5E,F). These results suggested that HupA had a significant anti-apoptotic effect on retinal neuronal injury induced by $\mathrm{I} / \mathrm{R}$ and OGD.

\section{The relationship between the retinal protective effects of HupA and the cholinergic system in retinal tissue and neurons subjected to I/R and OGD treatment}

To clarify the relationship between the retinal neuroprotective effects of HupA and the cholinergic system, AChE activity and acetylcholine (ACh) content were examined. As shown in Figure 6, the retinal neuronal injury induced by $\mathrm{I} / \mathrm{R}$ and OGD was accompanied by the dysfunction of the cholinergic system, including increased AChE activity and decreased ACh content. HupA and physostigmine significantly inhibited AChE activity $(\mathrm{P}<0.05$; Figure $6 A, C)$, while pilocarpine and latanoprost had no effect in the in vivo or in vitro experiments. In addition, HupA significantly increased ACh levels in retinal tissues and in cells (from $7.1 \pm 1.3$ to $12.4 \pm 4.0 \mathrm{ng} / \mathrm{mL}$ and from $0.24 \pm 0.17$ to $0.64 \pm 0.43 \mathrm{ng} / \mathrm{mL}$, respectively; $\mathrm{P}<0.001$; Figure $6 B, D)$. The above experiments demonstrated that the function of the cholinergic system was disturbed during the process of retinal nerve injury and it was restored after HupA treatment. Therefore, we speculated that the cholinergic system participates in the protective effect of HupA on retinal nerve function by inhibiting AChE activity to increase $\mathrm{ACh}$ concentration in retinal tissues or neurons and by activating mAChRs. However, it was unclear which mAChRs subtypes mediated the pharmacological effects of HupA and hence pharmacological methods, based on our previous study (18), were used to block the subtypes of mAChRs. In cultured PRNs, the effects of HupA on enhancing retinal nerve cells viability, maintaining the integrity of cell morphology, and reducing cytotoxicity induced by OGD were reversed by the non-selective mAChR antagonist atropine $(1 \mu M)$ and the selective M1 $\mathrm{mAChR}$ antagonist pirenzepine (Figure $6 E, F, G$ ). Atropine and pirenzepine treatment also reversed the anti-oxidative effects of HupA by decreasing the activity of SOD (Figure $6 H$ ), decreasing the GSH content (Figure 6I, $\mathrm{P}>0.05$ ), and increasing the levels of MDA significantly (Figure 67, $\mathrm{P}<0.05)$. Both atropine and pirenzepine upregulated the expression of caspase- 3 and $\mathrm{Bax} / \mathrm{Bcl}-2$ ratio $(\mathrm{P}<0.01$; Figure $6 K, L)$ compared with the group treated with HupA alone. The calcium flow analyses in the cytoplasm of CHO-M1 cells detected no signal in the HupA or physostigmine treatment groups, while a signal was detected in the pilocarpine group (Figure 6M). Therefore, the retinal neuronal protective effect of HupA was mediated by indirect activation of the $\mathrm{M} 1 \mathrm{mAChR}$ via inhibition of AChE activity to increase endogenous ACh level, rather than through direct stimulation of the choline receptors. These results suggested that HupA exerted a protective effect on PRN injury by increasing cell viability, decreasing OGD-induced cytotoxicity, and resisting oxidative stress related cell apoptosis. These effects were mediated by indirect activation of the M1 mAChR via inhibition of AChE activity to increase endogenous ACh level, rather than by direct stimulation of the receptors.

\section{The changes in the AKT/MAPK signaling patbway in the OGD treated primary retinal neurons}

While the neuroprotective effects of HupA appeared to be mediated by the M1 mAChR, the downstream signaling pathways are still unknown. It has been reported that the PI3K/AKT and the mitogen-activated protein kinase (MAPK) signaling pathways, including the extracellularsignal-regulated kinase 1/2 (ERK1/2), the c-Jun N-terminal kinases (JNK), and the p38 MAPK subgroups, play a key role in cell proliferation, cell cycle regulation, and initiation of apoptosis, all of which are closely related to the protective mechanisms of nervous system injury. In this experiment, the signaling pathway of OGD-induced retinal nerve cell injury and its regulation by HupA were further investigated. The phosphorylation levels of AKT, P38, ERK, and JNK changed after OGD treatment for 15, 30, 60, 120, and 240 minutes (Figure 7A,B). The levels of AKT, P38, ERK, and JNK phosphorylation after 60 minutes of OGD treatment were significantly different to the control group $(\mathrm{P}<0.05)$. At this point, the phosphorylation 
A
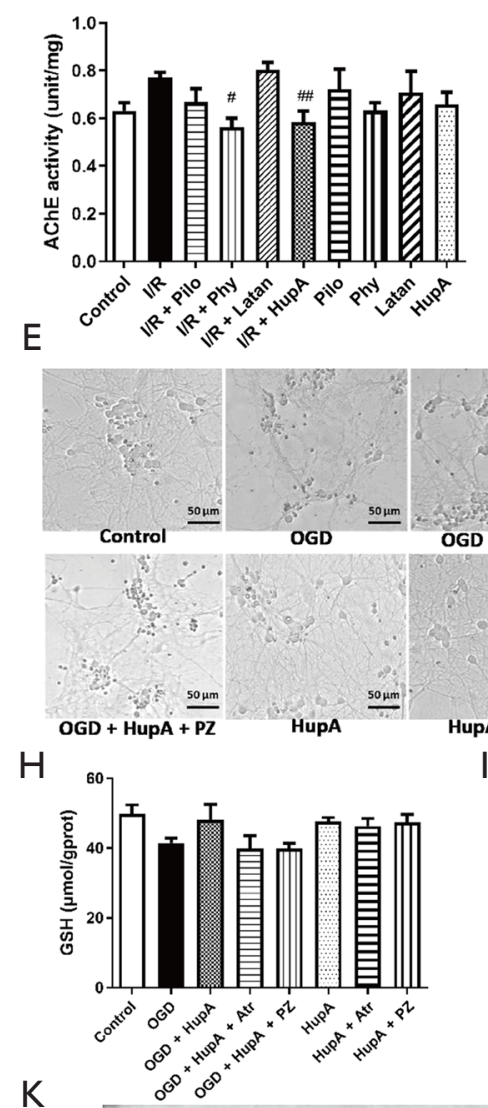

K

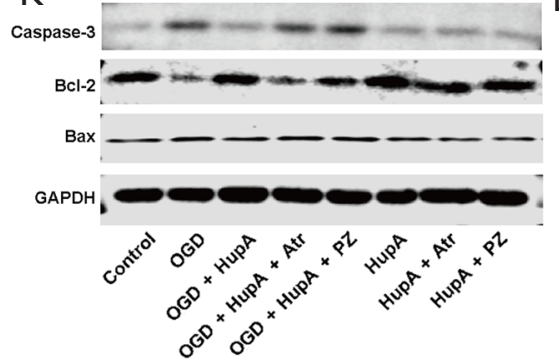

B

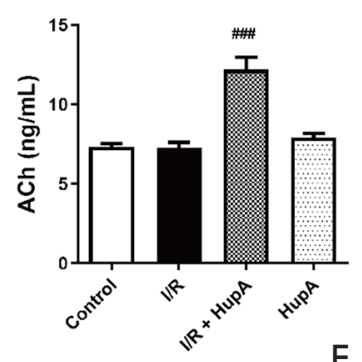

C

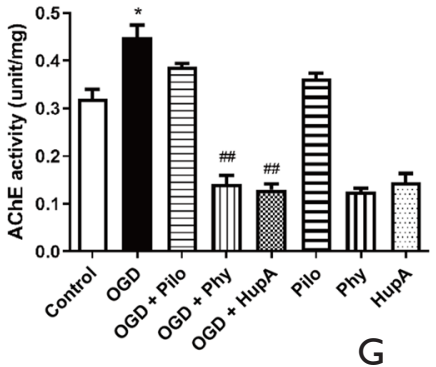

$\mathrm{D}$

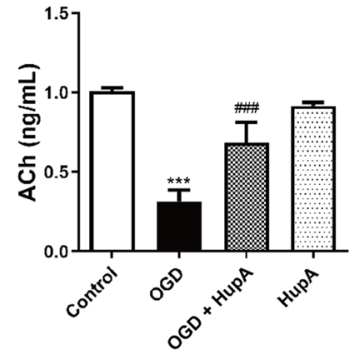

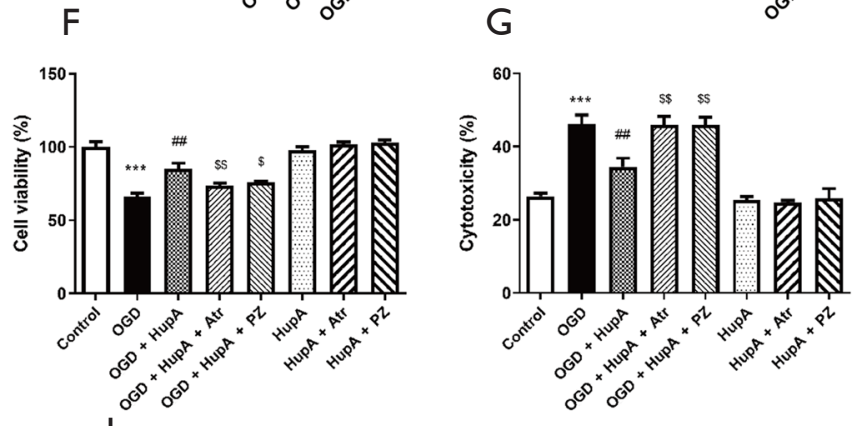
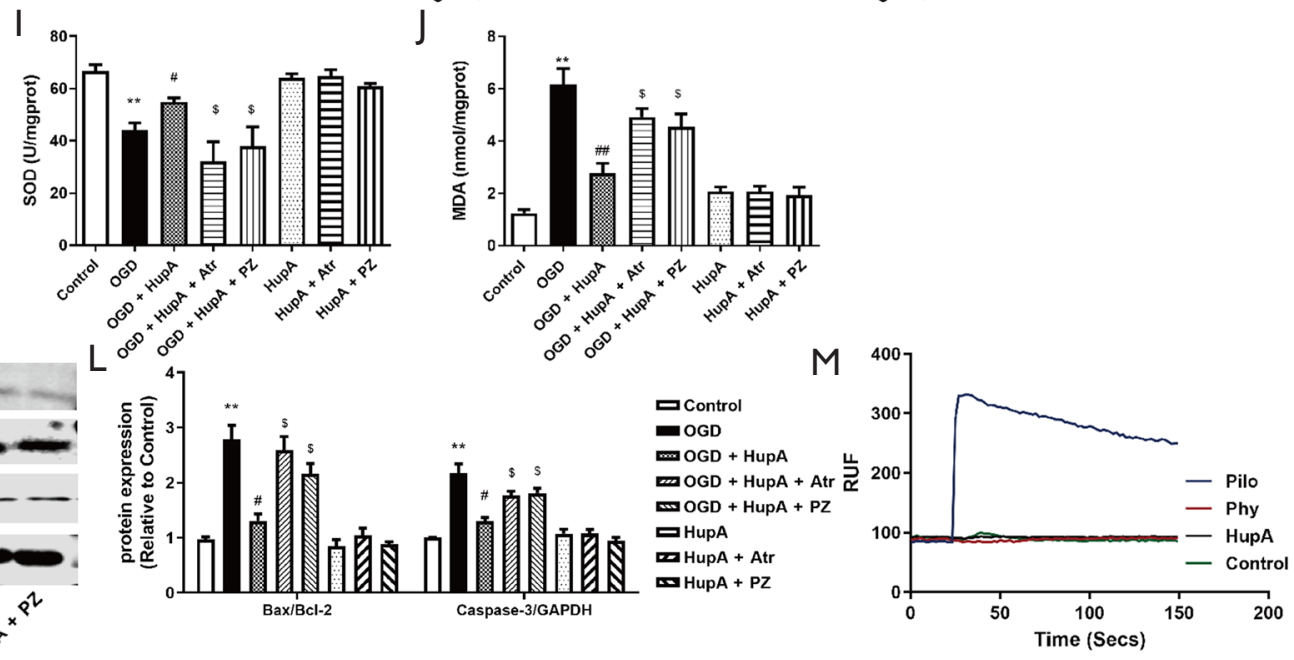

Figure 6 The disorder of the cholinergic system in retinal tissue and neurons induced by I/R and OGD could be reversed by HupA. This protective effect of HupA in OGD treated PRNs was reversed by the nonselective mAChR antagonist atropine and the M1 mAChR antagonist perizipine. (A,C) The AChE activity in rat retinal tissue and in PRNs subjected to OGD; (B,D) the levels of ACh detected by HPLC-MS/MS in rat retinal tissue and in PRNs subjected to OGD; (E) the photographs of PRNs in the different groups; (F) the retinal neuronal cell viability was detected by CCK-8 assay; (G) the cytotoxicity of the PRNs was detected by the LDH kit; (H) GSH levels in the OGD-treated PRNs; (I) SOD activity in retinal neurons; (J) MDA levels in retinal neurons; (K, L) the expression and analysis of caspase-3, Bcl-2, and Bax in PRNs subjected to OGD detected by western blotting after treatment with the M1 mAChR antagonists. (M) detection of the intracellular calcium flow in CHO-M1 after HupA, Phy, and Pilo treatment. Data are expressed as mean \pm SEM, $\mathrm{n} \geq 5$ rats or 3 independent experiments. ${ }^{*} \mathrm{P}<0.05,{ }^{* *} \mathrm{P}<0.01,{ }^{* * *} \mathrm{P}<0.001$, compared with the control group; ${ }^{\#} \mathrm{P}<0.05,{ }^{\# \#} \mathrm{P}<0.01$, compared with the I/R or OGD groups; ${ }^{\mathrm{S}} \mathrm{P}<0.05,{ }^{\mathrm{SS}} \mathrm{P}<0.01$, compared with the HupA group. HupA, huperzine A; I/R, ischemia/reperfusion; OGD, oxygen glucose deprivation; PRN, primary retinal neuron; Atr, atropine; PZ, perizipine; mAChR, muscarinic acetylcholine receptor; ACh, acetylcholine; HPLC-MS/MS, liquid chromatography-tandem mass spectrometry; CCK-8, cell counting kit 8; LDH, lactate dehydrogenase; GSH, glutathione; SOD, superoxide dismutase; MDA, malondialdehyde; Pilo, pilocarpine; Phy, physostigmine; Latan, latanoprost; GAPDH, glyceraldehyde 3-phosphate dehydrogenase; SEM, standard error of the mean. 
level of AKT had decreased to the lowest point, while the phosphorylation levels of P38, ERK, and JNK had increased to the highest point. Between 120 to 240 minutes, the phosphorylation levels of AKT, P38, ERK, and JNK gradually returned to normal levels. The results showed that the AKT/MAPK signaling pathway was involved in the process of OGD-induced retinal nerve injury, and the neuroprotective effects of HupA may be related to the AKT/MAPK signaling pathway.

To further clarify this relationship, retinal nerve cells were treated with HupA for 60 minutes after the induction of OGD. The results showed that HupA could significantly improve the phosphorylation of the AKT/MAPK signaling pathway-related proteins, by up-regulating the levels of P-AKT, and down-regulating the levels of P-P38, P-ERK, and P-JNK. The effects of HupA were blocked by atropine and pirenzepine, indicating that HupA regulated the phosphorylation of the AKT/MAPK signaling pathwayrelated proteins through the M1 mAChR (Figure 7C,D). Inhibitors of AKT, P38, ERK, and JNK were used to further investigate the role of the AKT/MAPK signaling pathway in retinal neuronal injury. While HupA increased cell viability after OGD treatment, the presence of the AKT inhibitor LY204002 counteracted these effects, resulting in decreased retinal neuronal cell viability compared to HupA group. The P38 inhibitor SB203580, the JNK inhibitor SP600125, and the ERK inhibitor U0126 all increased retinal neuronal cell viability following OGD treatment (Figure 7E). These results suggested that the retinal neuroprotective effects of HupA were mediated by the indirect activation of the M1 mAChR and its downstream AKT/MAPK signaling pathway.

\section{Discussion}

This study identified the dual mechanisms of HupA, that is, lowering IOP and providing retinal neuroprotection. HupA, at $0.01 \%$, was almost as effective as $2 \%$ pilocarpine at pupil contraction in the New Zealand rabbits. The in vitro experiments showed that HupA did not induce iris contraction and did not affect calcium flow. However, the ability of HupA to effect pupil contraction was antagonized by the M3 mAChR antagonist atropine and 4-DAMP, suggesting indirect activation of the $\mathrm{M} 3 \mathrm{mAChR}$. Experiments in I/R-induced rat retina and OGD-treated PRNs also demonstrated that HupA exerted a retinal neuroprotective effect by improving retinal pathological damage, increasing PRN cell viability, relieving oxidative stress, and reversing the apoptosis of retinal neurons. These retinal neuroprotective effects observed with HupA were antagonized by the M1 mAChR antagonist atropine and pirenzepine, suggesting that these effects were mediated through activation of the M1 mAChR. Furthermore, experiments assessing the AChE activity and ACh content detected in the retina and the PRNs, and the calcium flow signal detection experiments in $\mathrm{M} 1-\mathrm{CHO}$ cells showed that the retinal neuroprotective ability of HupA was mediated by indirect activation of the M1 mAChR. Since HupA exerts a dual effect of lowering IOP and protecting the retinal neuronal cells, it may be an effective agent in the treatment of glaucoma.

Up to now, lowering IOP, remains the principal proven method in glaucoma management. Topical medications have been considered the first approach which were divided into 5 classes: prostaglandin analogues, $\beta$-blockers, carbonic anhydrase inhibitors, cholinergic agonists and $\alpha$-agonists. Prostaglandin analogues or $\beta$-blockers was the first line drugs while second-line agents include $\alpha$-agonists and topical carbonic anhydrase inhibitors. Recently, rho kinase inhibitors have emerged as a new class of glaucoma medications to increase trabecular outflow which may soon be applied in glaucoma management according to the results of early clinical trials (23). While medical therapy could not get effective results for all patients, laser trabeculoplasty was an effective choice as a treatment modality to lower IOP and relay optic nerve damage. Surgical approach was considered when medical or laser treatment was insufficient in delaying the process of visual field defects.

Studies have reported that a part of patients still suffered progressive optic nerve damage and visual field loss with normal IOP. Neuroprotective treatments were conducted and explored with drugs targeting to inhibit neuroexcitation, reduce oxidative stress, decrease extrinsic or intrinsic apoptosis and deprive of internal neurotrophic factors. Other treatments including stem cell, gene therapy and viral research were also in the process of exploration $(24,25)$. These drugs were unsuccessful in the clinical trials or still in pre-clinical research stage. Based on the effectiveness of molecules currently available, novel drugs are believed to come into sight.

Cholinergic drugs have been used in the treatment of glaucoma for more than 100 years as a classic IOP-lowering medication, and its use can be traced back to the discovery of physostigmine in 1862 (26). AChEIs cause muscle contractions and promote aqueous humor outflows. AChEIs lower IOP by inhibiting AChE activity, thereby increasing ACh content at the junction of nerves and muscles, 

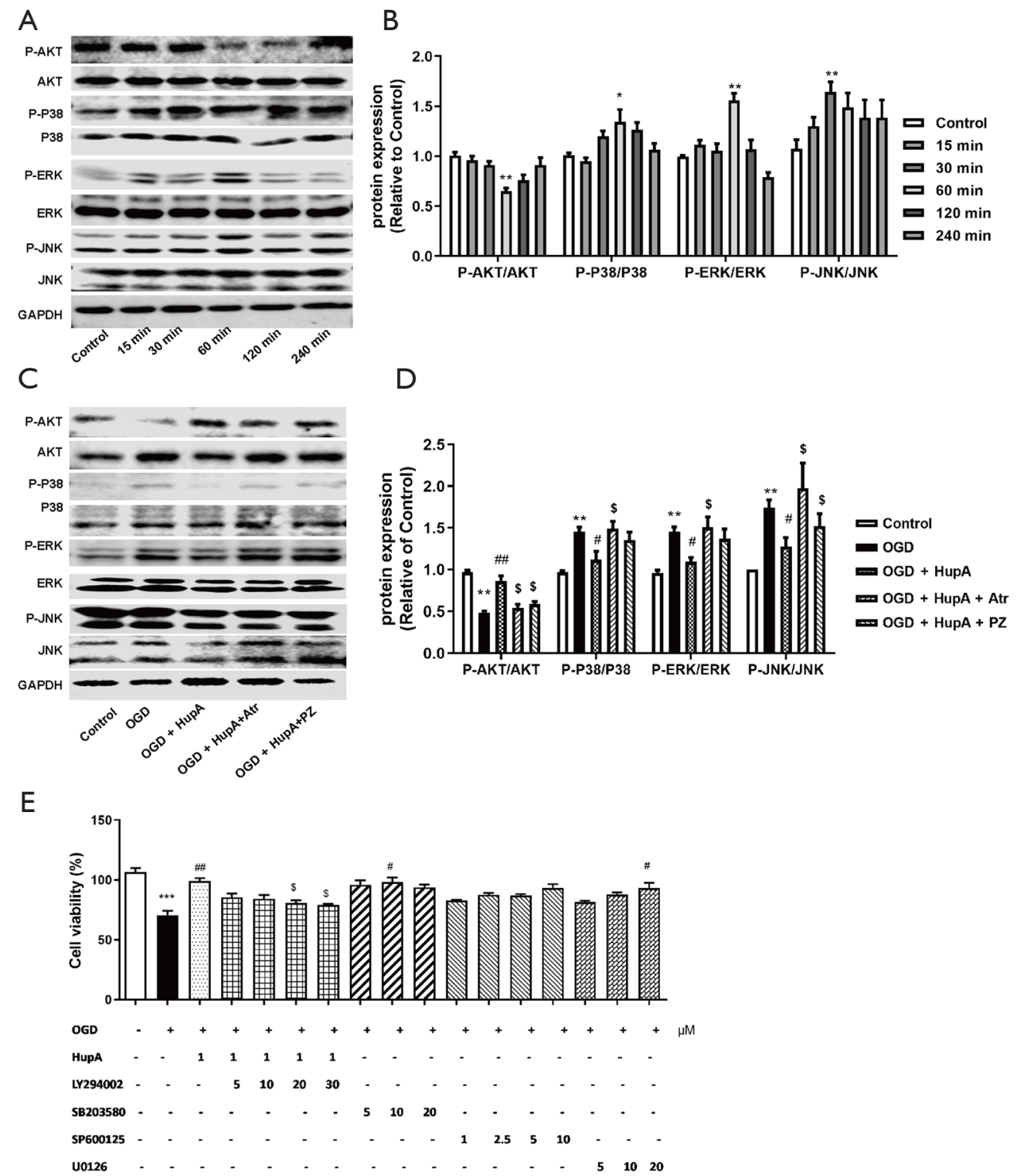

Figure 7 Involvement of AKT/MAPK signal pathway in the retinal neuroprotection of HupA. (A,C) Western blot analyses of the levels of phosphorylation of AKT, ERK, P38, and JNK in OGD- treated PRNs at different time points; (B,D) analyses of the level of phosphorylation of AKT, ERK, P38, and JNK treated by HupA and M1 mAChR antagonists; (E) effects of the AKT/MAPK pathway inhibitors on retinal neuronal cell viability. Data are expressed as mean $\pm \mathrm{SEM}, \mathrm{n} \geq 3$ independent experiments. ${ }^{*} \mathrm{P}<0.05$, ${ }^{* *} \mathrm{P}<0.01$, compared with the control group; ${ }^{\#} \mathrm{P}<0.05,{ }^{\prime \prime} \mathrm{P}<0.01$, compared with the OGD group; ${ }^{\$} \mathrm{P}<0.05$, compared with the HupA group. HupA, huperzine A; OGD, oxygen glucose deprivation; PRN, primary retinal neuron; Atr, atropine; PZ, perizipine; GAPDH, glyceraldehyde 3-phosphate dehydrogenase; P-AKT, phosphorylated AKT; P-P38, phosphorylated P38; ERK, extracellular-signal-regulated kinase 1/2; P-ERK, phosphorylated ERK; JNK, c-Jun N-terminal kinases; P-JNK, phosphorylated JNK; LY204002, AKT inhibitor; SB203580, P38 inhibitor; SP600125, JNK inhibitor; U0126, ERK inhibitor; SEM, standard error of the mean. 
resulting in the indirect stimulation of the mAChRs of the iris and ciliary muscles. The application of physostigmine in glaucoma has been discontinued due to its many peripheral side effects. Instead, pilocarpine, a mAChR agonist, is now used in combination with other drugs to lower IOP or as an alternative drug when glaucomatous patients are nonresponsive to other drugs in clinical practice. In this study, HupA treatment caused pupil contraction with a similar dosage-effect/time-effect relationship as pilocarpine and physostigmine. In fact, $0.01 \%$ HupA achieved a similar effect to the clinical dose of $2 \%$ pilocarpine. Therefore, HupA was more efficient at lowering IOP compared with pilocarpine. The M3 mAChR is the main receptor for cholinergic drugs to achieve the IOP-lowering effects (27). Our investigations confirmed that the IOP-lowering effects of HupA were blocked by the non-selective $\mathrm{mAChR}$ antagonist atropine and the selective $\mathrm{M} 3 \mathrm{mAChR}$ antagonist 4-DAMP, indicating the involvement of the $\mathrm{M} 3 \mathrm{mAChR}$. It has been reported in the literature that while HupA shows little direct binding to the mAChR, it does inhibit AChE activity (28). The in vitro experiments demonstrated that direct stimulation with HupA did not cause contraction of the isolated iris muscle and had no effect on the calcium flow signal in M3CHO cells, indicating an indirect excitatory effect on the mAChRs. Rather, the mechanism was related to inhibition of AChE activity, resulting in increased ACh content at the junction of the nerves and muscles, thereby indirectly activating the M3 mAChR to reduce IOP. The ability of HupA to reduce IOP via inhibition of AChE activity suggests that the use of AChEIs and HupA in the clinical treatment of glaucoma warrants further research.

In addition to the IOP-lowering effects, HupA was also shown to have retinal neuroprotective effects. Interestingly, HupA also has multiple neuroprotective effects in AD patients. Glaucoma is a chronic degenerative disease of the optic nerve and shares a similar pathological process with $\mathrm{AD}$. In addition to lowering IOP, future glaucoma treatment strategies should aim to protect the optic nerve (29). This study found that HupA could prevent I/R and OGDinduced retinal neuronal injury. After HupA treatment, the thickness of the whole retinal, IPL, and INL were increased, the number of RGCs in the GCL was increased, and the decreased expression of the retinal neuronal specific markers Thy1, Felmc, Scng, Nrnl, and Nfl was reversed. All these indicated that HupA improved the retinal pathologic lesion. HupA treatment also improved the neuronal cell viability following OGD treatment. Oxidative stress induced by $\mathrm{I} / \mathrm{R}$ and OGD was mitigated by increasing
SOD activity and GSH levels, decreasing MDA content, and regulating apoptosis-related protein expression such as decreasing $\mathrm{Bax} / \mathrm{Bcl}-2$ ratio and caspase- 3 expression. Multi-targeted treatment strategies combined with retinal neuronal protection may be more effective in alleviating the progression of glaucoma disease than treatments singularly targeted at IOP. Therefore, HupA may have great clinical potential in glaucoma treatment.

The retina is a tissue with abundant blood supply and high metabolic activity. Oxidative stress is an important risk factor for the development of human glaucoma (30). High IOP itself can cause insufficient blood supply to the retina, and the process of $\mathrm{I} / \mathrm{R}$ can also cause oxidative stress injury. High levels of reactive oxygen species (ROS) can oxidize unsaturated fatty acids in lipids, and amino acids in proteins, causing irreversible damage to important organelles and DNA. This ultimately leads to cell apoptosis and necrosis. Therefore, neuronal cell apoptosis induced by oxidative stress is the final pathway of neurodegenerative diseases such as glaucoma (30-32). It has been reported that plasma levels of oxidative stress-related factors, such as antioxidant GSH, continue to decrease in glaucoma patients (33) and oxidative DNA damage and mitochondrial dysfunction have also been confirmed (34). Intracellular ROS scavenging endogenous antioxidants (including SOD and GSH) have been shown to produce a retinal neuroprotective effect. The antioxidants improved the intracellular GSH levels and prevented apoptosis of RGCs and loss of optic nerve axons in experimental models of glaucoma $(35,36)$. In this current study, we confirmed that the I/R-induced damage to the rat retina and the OGD-induced damage to the PRNs were associated with the imbalance of oxidative stress conditions, including significantly decreased intracellular GSH levels and SOD activity, and the increased generation of MDA. However, HupA could significantly restore the abnormal levels of SOD, GSH, and MDA, thereby alleviating the oxidative stress-related retinal neuronal damage.

Retinal neuronal damage caused by oxidative stress is closely related to intracellular apoptosis which is believed to be the common terminal pathway in neurodegenerative diseases such as glaucoma. Progressive loss of RGCs has been shown to be related to apoptosis, and as such, it is a key pathway to protect RGCs in glaucoma therapy $(37,38)$. Bcl2 and Bax are two members of the Bcl-2 gene family which represents a large proportion of the whole progenitor apoptotic pathway (39). Previous studies using a model of optic nerve injury, showed that up-regulated $\mathrm{Bcl}-2$ protein expression effectively promoted RGCs survival, while Bax promoted 
RGC apoptosis and death. The apoptosis of the RGCs was dependent on caspase- 3 activity. Inhibiting caspase-3 effectively improved the optic neuropathy and promoted visual recovery by reducing the apoptosis of RGCs (40). Similarly, this current investigation demonstrated that the incidence of RGC apoptosis was significantly increased following I/R and OGD with significantly increased caspase- 3 expression and $\mathrm{Bax} / \mathrm{Bcl}-2$ ratio. This indicated that the activation of the retinal nerve cell apoptosis pathway occurred under I/R and OGD-induced oxidative stress. However, after HupA treatment, the abnormal expression of apoptosis-related proteins was significantly reversed, and the survival rate of the PRNs was also significantly improved along with the retinal pathology. This indicated that HupA played a retinal neuroprotective role by combating oxidative stress-induced apoptosis.

As HupA is an AChEI, the retinal neuroprotective effects might be related to its cholinergic function. It has been reported that dysfunction of the cholinergic system is an important factor in neurodegenerative diseases such as $\mathrm{AD}$ (41). AChEIs inhibit AChE activity, thereby reducing the hydrolysis of $\mathrm{ACh}$ and resulting in improved levels and action time of endogenous ACh. This can produce certain therapeutic effects on patients with neurodegenerative diseases (42). ACh in retinal tissue is mainly found in certain cholinergic neurons (amacrine neurons) located in the core layer and extend to the ganglion cells (43). In our previous study, levels of choline acetyltransferase (ChAT), which is responsible for ACh synthesis in the retinal nerve, was found to be significantly decreased in the I/R-induced retinal injury model indicating that cholinergic system disorders accompanied with retinal neuronal damage (18). It has also been reported that oxidative stress induced neuronal cells injury with significantly increased AChE activity, while AChEIs reversed the process and maintained the neuronal function (44). This is in agreement with our experiments demonstrating that I/R and OGD-induced oxidative injury and apoptosis of the retinal neurons were accompanied by dysfunction of the cholinergic system. Retinal neuronal cells subjected to OGD showed increased AChE activity and decreased ACh level. However, HupA treatment significantly improved the dysfunction of the cholinergic system by inhibiting AChE activity, and increasing the ACh levels in retinal nerve tissue and PRNs of the I/R and OGD models. Studies have shown that the M1-M5 choline receptors are expressed in retinal bipolar cells, secretory cells, and ganglion cells (45). Cholinergic drugs may play different regulatory roles through choline receptors. In experimental glaucoma models, the cholinesterase inhibitor galantamine promoted the survival of RGCs and its axons, and its neuroprotective effect was mainly mediated by activation of the retinal M1 mAChRs (46). Our previous studies also demonstrated that $\mathrm{mAChR}$ agonists (pilocarpine, L-satropine, and carbachol) promoted neuronal cell survival via activating the M1 mAChR $(17,47)$. In this study we identified that HupA could reverse retinal oxidative stress and neuronal cell apoptosis. These effects were counteracted by the nonselective $\mathrm{mAChR}$ antagonist atropine and the selective M1 mAChR antagonist pirenzepine, suggesting that the retinal neuronal protective effect of HupA was achieved by activating the M1 mAChR. The calcium flow signal detection experiments in CHO-M1 cells indicated no direct excitatory effect of HupA on the M1 mAChR. All these results suggested that HupA stimulated the M1 mAChR indirectly and the retinal neuronal protective effects were mediated by inhibition of AChE activity and increasing the endogenous ACh content.

We further investigated the downstream signaling pathway of M1 mAChR activation. It has been reported that PI3K/AKT signaling plays a key role in cell proliferation, cell cycle regulation, and initiation of apoptosis, all of which are closely related to the protective mechanisms in nervous system injury (48). In addition, the MAPK signaling pathway, involving ERK, P38 and JNK, is also closely related to the occurrence and repair of nervous system injury. Multiple types of injury can cause abnormal phosphorylation of related molecules which are then gathered to the injured site and participate in the process of neuronal cell apoptosis (49). Activation of AKT by SC79, a unique specific AKT activator, augmented neuronal survival in a hippocampal neuronal culture system and a mouse model for ischemic stroke (50). Phosphorylated JNK was involved in the apoptotic and inflammatory mechanisms of neuronal damage while the use of JNK activator anisomycin reverse the neuroprotective effects of echinocystic acid (51). In retinal neuronal injury, treatment with inhibitors of AKT and agonists of $\mathrm{P} 38$ and JNK enhanced the retinal neuronal apoptosis by increasing the expression of apoptosis-related proteins such as caspase-3 (52). All the studies indicated the involvement of AKT/MAPK signal pathway in the process of retinal neuronal injury. In this study, OGD resulted in retinal nerve cell damage accompanied by decreased phosphorylation of AKT and increased phosphorylation of P38, ERK, and JNK. These results suggested that these signaling pathway molecules might be involved in the process of retinal neuronal injury induced by OGD. The OGD-induced phosphorylation of the unbalance AKT/ 
MAPK signaling pathway was corrected by HupA, and this correction was partially blocked by the $\mathrm{M} 1 \mathrm{mAChR}$ antagonists atropine and pirenzepine. In addition, the AKT inhibitor blocked the effects of HupA, while P38/ERK/ JNK inhibitors reversed the OGD-induced cytotoxicity and enhanced the activity of retinal nerve cells. These results indicated that the AKT/MAPK pathway was involved in OGD-induced retinal neuronal injury, and HupA achieved its retinal neuroprotective effect by activating the $\mathrm{M} 1 \mathrm{mAChR}$ and the downstream AKT/MAPK signaling pathway.

The aim of glaucoma treatment is to reduce the damage to the optic nerve. Therefore, it is an important strategy to develop drugs that can reduce IOP and protect the optic nerve. This investigation used both in vivo and in vitro glaucoma retinal injury models. HupA significantly reversed the retinal pathological damage, increased the retinal nuclear layer and inner plexiform layer thickness, reduced RGC death, and increased the expression of retinal neural specific proteins Fem1c, Sncg, Thy1, Nrn1, and Nfl. The protective effects of HupA on the optic nerve was related to the regulation of oxidative stress by affecting the expression of apoptosis-related proteins (caspase-3, Bcl-2, and Bax). The actions of HupA were mediated by inhibiting AChE activity, thereby increasing the levels of $\mathrm{ACh}$, and indirectly stimulating the M1 mAChR. While this study assessed the role of the AKT/MAPK signaling pathway and the related molecular proteins in the protective effect of HupA against optic nerve injury, it did not fully elucidate the mechanisms of action. Future research will be required to investigate new potential regulatory mechanisms which will provide support for the use of HupA in glaucoma treatment.

\section{Acknowledgments}

Funding: This study was supported by Major national innovation and development science and technology projects (No.2014ZX09104002-005).

\section{Footnote}

Reporting Checklist: The authors have completed the ARRIVE reporting checklist. Available at http://dx.doi. org/10.21037/atm-20-8093

Data Sharing Statement: Available at http://dx.doi. org/10.21037/atm-20-8093

Conflicts of Interest: All authors have completed the ICMJE uniform disclosure form (available at http://dx.doi. org/10.21037/atm-20-8093). The authors have no conflicts of interest to declare.

Ethical Statement: The authors are accountable for all aspects of the work in ensuring that questions related to the accuracy or integrity of any part of the work are appropriately investigated and resolved. This study was approved by the Shanghai Jiao Tong University School of Medicine Institutional Animal Care \& Use Committee (No. A-2015-044). Experiments were performed in compliance with the principles and guidelines of the National Institutes of Health Guide for the Care and Use of Laboratory Animals.

Open Access Statement: This is an Open Access article distributed in accordance with the Creative Commons Attribution-NonCommercial-NoDerivs 4.0 International License (CC BY-NC-ND 4.0), which permits the noncommercial replication and distribution of the article with the strict proviso that no changes or edits are made and the original work is properly cited (including links to both the formal publication through the relevant DOI and the license). See: https://creativecommons.org/licenses/by-nc-nd/4.0/.

\section{References}

1. Tham YC, Li X, Wong TY, et al. Global prevalence of glaucoma and projections of glaucoma burden through 2040: a systematic review and meta-analysis. Ophthalmology 2014;121:2081-90.

2. Kim JH, Caprioli J. Intraocular Pressure Fluctuation: Is It Important? J Ophthalmic Vis Res 2018;13:170-4.

3. Agar A, Li S, Agarwal N, et al. Retinal ganglion cell line apoptosis induced by hydrostatic pressure. Brain Res 2006;1086:191-200.

4. Wojcik-Gryciuk A, Skup M, Waleszczyk WJ. Glaucoma -state of the art and perspectives on treatment. Restor Neurol Neurosci 2016;34:107-23.

5. Eraslan M, Cerman E, Cekic O, et al. Neurodegeneration in ocular and central nervous systems: optical coherence tomography study in normal-tension glaucoma and Alzheimer disease. Turk J Med Sci 2015;45:1106-14.

6. Mancino R, Martucci A, Cesareo M, et al. Glaucoma and Alzheimer Disease: One Age-Related Neurodegenerative Disease of the Brain. Curr Neuropharmacol 2018;16:971-7.

7. Inoue T, Kawaji T, Tanihara H. Elevated levels of multiple biomarkers of Alzheimer's disease in the aqueous humor of 
eyes with open-angle glaucoma. Invest Ophthalmol Vis Sci 2013;54:5353-8.

8. Bayer AU, Ferrari F, Erb C. High occurrence rate of glaucoma among patients with Alzheimer's disease. Eur Neurol 2002;47:165-8.

9. Kesler A, Vakhapova V, Korczyn AD, et al. Retinal thickness in patients with mild cognitive impairment and Alzheimer's disease. Clin Neurol Neurosurg 2011;113:523-6.

10. Szegedi S, Dal-Bianco P, Stogmann E, et al. Anatomical and functional changes in the retina in patients with Alzheimer's disease and mild cognitive impairment. Acta Ophthalmol 2020;98:e914-21.

11. McKinnon SJ. Glaucoma: ocular Alzheimer's disease? Front Biosci 2003;8:s1140-56.

12. Zhang HY. New insights into huperzine A for the treatment of Alzheimer's disease. Acta Pharmacol Sin 2012;33:1170-5.

13. Yan H, Zhang HY, Tang XC. Involvement of M1muscarinic acetylcholine receptors, protein kinase $\mathrm{C}$ and mitogen-activated protein kinase in the effect of huperzine A on secretory amyloid precursor protein-alpha. Neuroreport 2007;18:689-92.

14. Wang J, Zhang HY, Tang XC. Huperzine a improves chronic inflammation and cognitive decline in rats with cerebral hypoperfusion. J Neurosci Res 2010;88:807-15.

15. Cui W, Cui GZ, Li W, et al. Bis(12)-hupyridone, a novel multifunctional dimer, promotes neuronal differentiation more potently than its monomeric natural analog huperzine A possibly through alpha7 nAChR. Brain Res 2011;1401:10-7.

16. Cui W, Hu S, Chan HH, et al. Bis(12)-hupyridone, a novel acetylcholinesterase inhibitor, protects against glutamateinduced neuronal excitotoxicity via activating alpha7 nicotinic acetylcholine receptor/phosphoinositide 3-kinase/ Akt cascade. Chem Biol Interact 2013;203:365-70.

17. Yu P, Zhou W, Liu L, et al. L-Satropane Prevents Retinal Neuron Damage by Attenuating Cell Apoptosis and Abeta Production via Activation of M1 Muscarinic Acetylcholine Receptor. Curr Eye Res 2017;42:1319-26.

18. Tan PP, Yuan HH, Zhu X, et al. Activation of muscarinic receptors protects against retinal neurons damage and optic nerve degeneration in vitro and in vivo models. CNS Neurosci Ther 2014;20:227-36.

19. Xu ZP, Devillier P, Xu GN, et al. TNF-alpha-induced CXCL8 production by A549 cells: involvement of the nonneuronal cholinergic system. Pharmacol Res 2013;68:16-23.

20. Schmitt HM, Pelzel HR, Schlamp CL, et al. Histone deacetylase 3 (HDAC3) plays an important role in retinal ganglion cell death after acute optic nerve injury. Mol Neurodegener 2014;9:39.

21. Sacca SC, Bolognesi C, Battistella A, et al. Geneenvironment interactions in ocular diseases. Mutat Res 2009;667:98-117.

22. Ahmad A, Ahsan H. Biomarkers of inflammation and oxidative stress in ophthalmic disorders. J Immunoassay Immunochem 2020;41:257-71.

23. Conlon R, Saheb H, Ahmed, II. Glaucoma treatment trends: a review. Can J Ophthalmol 2017;52:114-24.

24. Yadav KS, Sharma S, Londhe VY. Bio-tactics for neuroprotection of retinal ganglion cells in the treatment of glaucoma. Life Sci 2020;243:117303.

25. Gossman CA, Christie J, Webster MK, et al. Neuroprotective Strategies in Glaucoma. Curr Pharm Des 2016;22:2178-92.

26. Realini T. A history of glaucoma pharmacology. Optom Vis Sci 2011;88:36-8.

27. Zhu L, Cui YY, Feng JM, et al. Aceclidine and pilocarpine interact differently with muscarinic receptor in isolated rabbit iris muscle. Life Sci 2006;78:1617-23.

28. Tang XC, De Sarno P, Sugaya K, et al. Effect of huperzine A, a new cholinesterase inhibitor, on the central cholinergic system of the rat. J Neurosci Res 1989;24:276-85.

29. He S, Stankowska DL, Ellis DZ, et al. Targets of Neuroprotection in Glaucoma. J Ocul Pharmacol Ther 2018;34:85-106.

30. Benoist d'Azy C, Pereira B, Chiambaretta F, et al. Oxidative and Anti-Oxidative Stress Markers in Chronic Glaucoma: A Systematic Review and Meta-Analysis. PLoS One 2016;11:e0166915.

31. Tezel G. Oxidative stress in glaucomatous neurodegeneration: mechanisms and consequences. Prog Retin Eye Res 2006;25:490-513.

32. He Z, Vingrys AJ, Armitage JA, et al. The role of blood pressure in glaucoma. Clin Exp Optom 2011;94:133-49.

33. Gherghel D, Mroczkowska S, Qin L. Reduction in blood glutathione levels occurs similarly in patients with primary-open angle or normal tension glaucoma. Invest Ophthalmol Vis Sci 2013;54:3333-9.

34. Sacca SC, Pascotto A, Camicione P, et al. Oxidative DNA damage in the human trabecular meshwork: clinical correlation in patients with primary open-angle glaucoma. Arch Ophthalmol 2005;123:458-63.

35. Payne AJ, Kaja S, Naumchuk Y, et al. Antioxidant drug therapy approaches for neuroprotection in chronic diseases of the retina. Int J Mol Sci 2014;15:1865-86. 
36. Inman DM, Lambert WS, Calkins DJ, et al. alphaLipoic acid antioxidant treatment limits glaucoma-related retinal ganglion cell death and dysfunction. PLoS One 2013;8:e65389.

37. Kimura A, Namekata K, Guo X, et al. Targeting Oxidative Stress for Treatment of Glaucoma and Optic Neuritis. Oxid Med Cell Longev 2017;2017:2817252.

38. Wang H, Zhang C, Lu D, et al. Oligomeric proanthocyanidin protects retinal ganglion cells against oxidative stress-induced apoptosis. Neural Regen Res 2013;8:2317-26.

39. Ko ML, Chen CF, Peng PH, et al. Simvastatin upregulates Bcl-2 expression and protects retinal neurons from early ischemia/reperfusion injury in the rat retina. Exp Eye Res 2011;93:580-5.

40. Sanchez-Migallon MC, Valiente-Soriano FJ, NadalNicolas FM, et al. Apoptotic Retinal Ganglion Cell Death After Optic Nerve Transection or Crush in Mice: Delayed RGC Loss With BDNF or a Caspase 3 Inhibitor. Invest Ophthalmol Vis Sci 2016;57:81-93.

41. Sharma K. Cholinesterase inhibitors as Alzheimer's therapeutics. Mol Med Rep 2019;20:1479-87.

42. Hampel H, Mesulam MM, Cuello AC, et al. The cholinergic system in the pathophysiology and treatment of Alzheimer's disease. Brain 2018;141:1917-33.

43. Vaney DI, Peichi L, Boycott BB. Matching populations of amacrine cells in the inner nuclear and ganglion cell layers of the rabbit retina. J Comp Neurol 1981;199:373-91.

44. Guesmi F, Bellamine H, Landoulsi A. Hydrogen peroxideinduced oxidative stress, acetylcholinesterase inhibition, and mediated brain injury attenuated by Thymus algeriensis. Appl Physiol Nutr Metab 2018;43:1275-81.

45. Strang CE, Renna JM, Amthor FR, et al. Muscarinic

Cite this article as: Yu P, Dong WP, Tang YB, Chen HZ, Cui YY, Bian XL. Huperzine A lowers intraocular pressure via the $\mathrm{M} 3 \mathrm{mAChR}$ and provides retinal neuroprotection via the M1 mAChR: a promising agent for the treatment of glaucoma. Ann Transl Med 2021;9(4):332. doi: 10.21037/atm-20-8093 acetylcholine receptor localization and activation effects on ganglion response properties. Invest Ophthalmol Vis Sci 2010;51:2778-89.

46. Almasieh M, Zhou Y, Kelly ME, et al. Structural and functional neuroprotection in glaucoma: role of galantamine-mediated activation of muscarinic acetylcholine receptors. Cell Death Dis 2010;1:e27.

47. Ma K, Yang LM, Chen HZ, et al. Activation of muscarinic receptors inhibits glutamate-induced GSK3 beta overactivation in PC12 cells. Acta Pharmacol Sin 2013;34:886-92.

48. Liot G, Gabriel C, Cacquevel M, et al. Neurotrophin-3induced PI-3 kinase/Akt signaling rescues cortical neurons from apoptosis. Exp Neurol 2004;187:38-46.

49. Lee ER, Kim JY, Kang YJ, et al. Interplay between PI3K/Akt and MAPK signaling pathways in DNAdamaging drug-induced apoptosis. Biochim Biophys Acta 2006;1763:958-68.

50. Jo H, Mondal S, Tan D, et al. Small molecule-induced cytosolic activation of protein kinase Akt rescues ischemiaelicited neuronal death. Proc Natl Acad Sci U S A 2012;109:10581-6.

51. Yu H, Li W, Cao X, et al. Echinocystic acid, a natural plant extract, alleviates cerebral ischemia/reperfusion injury via inhibiting the JNK signaling pathway. Eur J Pharmacol 2019;861:172610.

52. Zhang TZ, Hua T, Han LK, et al. Antiapoptotic role of the cellular repressor of E1A-stimulated genes (CREG) in retinal photoreceptor cells in a rat model of light-induced retinal injury. Biomed Pharmacother 2018;103:1355-61.

(English Language Editor: J. Teoh) 